\author{
Estimates of the Hidth of the \\ Wetting Zone Along a Fracture Subjected to an \\ Episodic Infiltration Event in Variat, \\ Saturated, Densely Helded Tuff
}

Thomas A. Buscheck

and

John U. Nitao

May 31, 1988

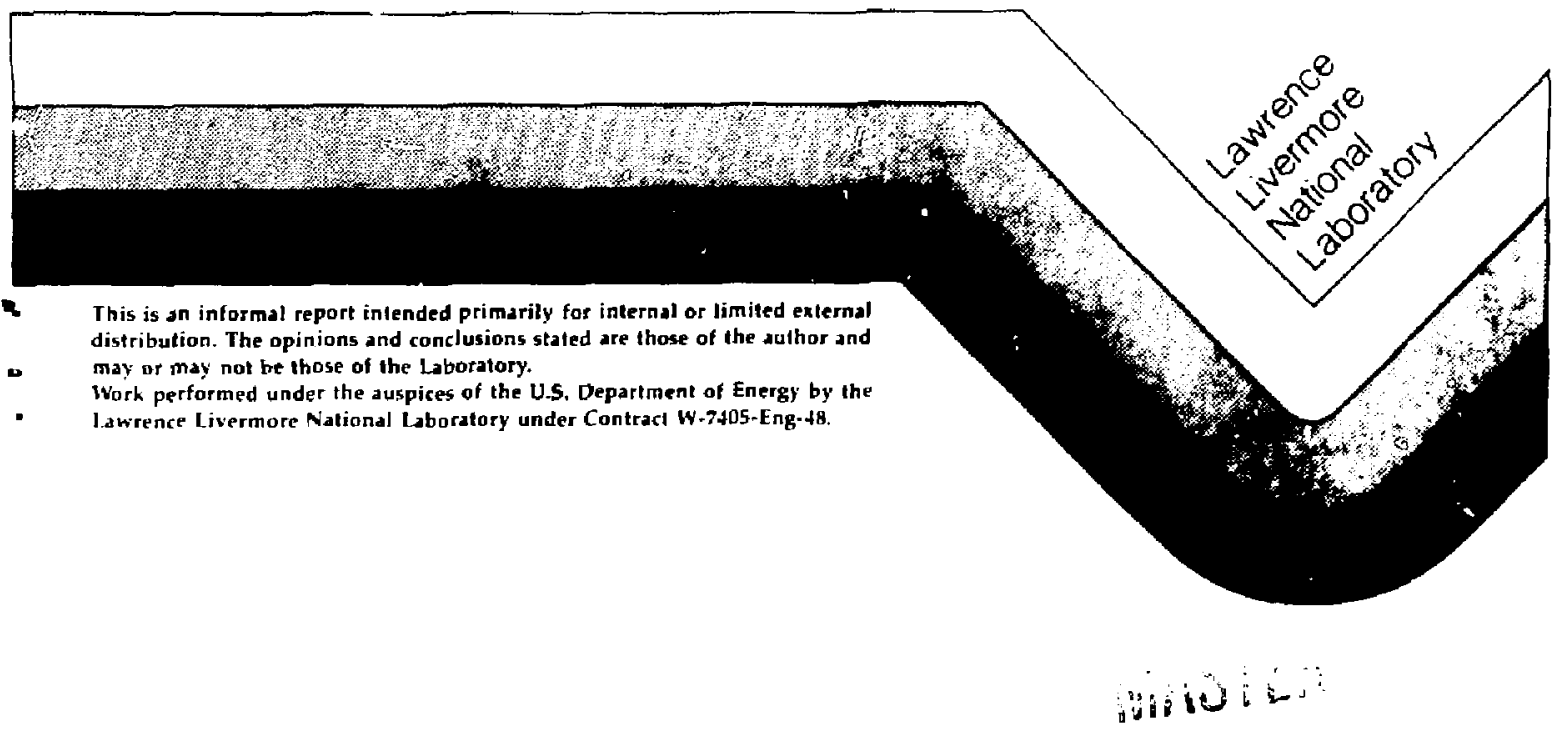




\title{
Estimates of the Width of the Wetting Zone Along a Fracture Subjected to an Episodic Infiltration Event in Variably Saturated, Densely Welded Tuff
}

\author{
Thomas A. Buscheck and John J. Nirao \\ Lawrence Livermore National Laboratory
}

\begin{abstract}
A central issue to be addressed within the Nevada Nuclear Waste Storige Invesligations (NNWSI) is the fole which fractures will play as the variably saluraled, fractured rxck mass surrounding the waste package responds to healing, cooling, and episodic infiluation cvents. Understanding the mole of fmetures during such events will, in part, depeno on our ability to make geophysical measurements of perturbations in the moisture distribution in the vicinity of fractures. In this study ve first examine the details of tin perturbation in the moisture distribution in and around a fracure subjected to an episodic infiltration event, and then integrale that behavior over the scale al which moisture measurements are likely to be made during the Engineered Barrier Design Test of the NNWSI project. To model this system we use the TOUGH hydrothemal code and fracture and malrix properties considered relevant to the welded ash flow tuff found in the Topopah Spring member al Yucea Mountain as well as in the Grouse Canyon member within G-Tunnel at the Nevada Test Site. Our calculations provide insight into the anticipated spatial and temporal resolution obtainable through the use of the geophysical lechniques being considered. These calculations should prove useful both in piasning the implementation of these methods as well as in the interpretation of their results.
\end{abstract}

\section{DISCLAIMER}

\footnotetext{
This repon was prepared at an account of work sponsored by an azency of the Unitod Siates Government. Neither the Linited Staln Government nor any agency thereof. nor any of their emptoyta makes any wartanty. exptos of implied. Of assumes any legal liability of responsibiliny for the accuracy, completeness, of usefulness of any information, apparalus. product. or pacess disclowed, of represents that its use would not infinge prtvately owned nghts. Referense herein to any specific commercial produzt, process. or serice by trade name. erademark. imanufacturer. of othermse does nol necesunly constitute or imply its endorsement, recommendation. of favoring by the United Siates Government or enj agency thereol The vxems and opinions of avibors expresed hesetn do not necessarily stale or reflect those of the Unitod Stata Governmenl or any agency thercol
} 


\section{Table of Contents}

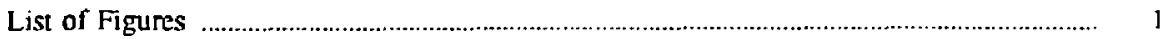

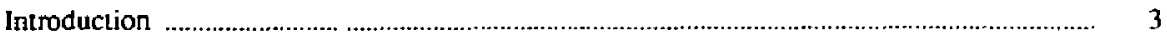

1. Problem Description ................................................................................................. 5

2. Modeling Approach .......................................................................................... 7

2.1 Code Description ............................................................................................ 7

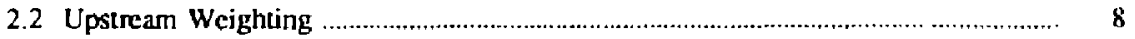

3. Discussion of Physical Data and Assumptions ........................................................... 9

3.1 Matrix Properties .................................................................................................. 9

3.2 The Effect of Hysteresis on Moisture Retention .................................................... 11

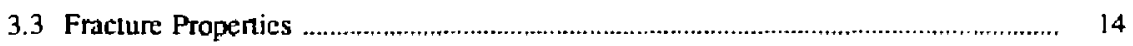

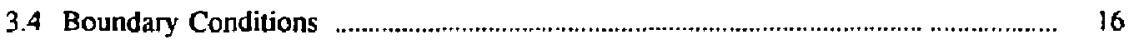

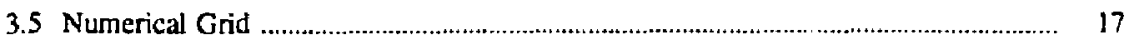

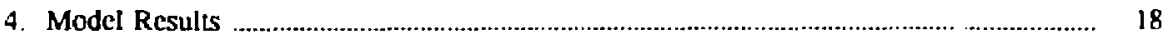

4.1 Two-Dimensional Model of Fracture Flow and Matrix Imbibition ............................ 18

4.2 The Applicability of the One-Dimensional Model of Matrix Imbibition ................... 20

4.3 Parameter Sensitivity of Matrix Imbibition .............................................................. 22

4.4 The Decay of the Infiltration Slug in the Fracture .............................................. 24

4.5 The Decay of the Imbibition Mound in the Matrix ............................................... 26

5. Interpreting Model Results With Respect to Gcophysical Surveys ................................... 27

5.1 Geophysical Signature During the Decay of the Imbibition Mound ......................... 27

5.2 Geolomographic Signalure of the Welting Zone ............................................ 28

5.3 Neutron Tool Signature of the Welting Zone ..................................................... 32

6. Summary and Conclusions ............................................................................................ 33

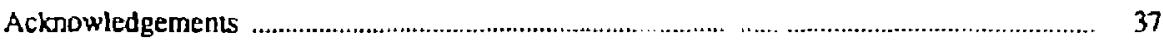

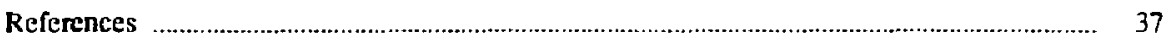

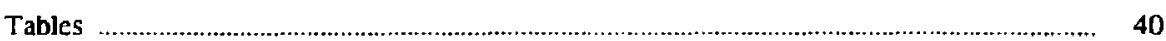

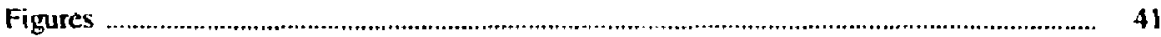




\section{List of Figures}

Figure 1. Liquid relative permeability versus liquid saluration for sample G4-6 cored at a depth of 1158 feet within the repository horizon at Yueca Mouniain.

Figure 2. Log of the ahsolute value of suction head versus liquid saturation for sample G4-6 cored at a depth of 1158 fect within the repository horizon al Yucca Mountain.

Figure 3. Hysteresis in the moisture retention curve (taken from Bear 1979).

Figure 4. Hysteresis in the moisture retention curve. This example is an extrapolation of data observed in Buscheck and Nitao (1987).

Figl ie 5. Hysteresis in the moisture retention curve. This example is an extrapolation of dala obser id in Buschock and Nitav (1987) assuming that air entrapment occurs at $92 \%_{6}$ salurstion.

Figure 6. Liquid relalive permeability versus lequid saluration for the 50 and $100 \mu \mathrm{m}$ fracture

Figure 7. Log of the absolute value of suction pressure versus liquid saturation for the $100 \mu \mathrm{m}$ fraclure.

Figure \$. Log of the absolute value of suction pressure versus liquid saluration for the $50 \mathrm{\mu m}$ fracture.

Figure 9. Liquid saturation disurbulion around a $50 \mu \mathrm{m}$ fracture at the end of the 2 day "arcive" stage of the infiltration event. Noxe that the figure is rotated $90^{\circ}$ counterclockwise and that horizontal distances are exaggerated by a factor of 143 .

Figure 10. Liquid saturation distritution around a $100 \mathrm{\mu n}$ fracture at the cnd of the 2 day "active" stage of the infeltration event Noes that the figure is rotated $90^{\circ}$ counterclockwise and that horizontal distances are exaggeraicd by a factor of 1000 .

Figure 11. The $82.5 \%$ saturation conbur in the vicinity of a $50 \mu \mathrm{m}$ fraclure plolted every 2 hours during the 2 day "artive" sage of the infiltration event. Note that the figure is rotated 90 counterelockwise and that horizontal distances are cxaggerated by a factor of 143.

Figure 12. The 82.5\% saluration contour in the vicinity of a $100 \mu \mathrm{m}$ fracture plotied every 2 hours during the 2 day "active" stage of the infiltration cvent. Note that the figure is rotated $90^{\circ}$ counterclocku-ise and that horizontal distances are exaggerated by a factor of 1000 .

Figure 13. Latgud saturation profile along centcrline of a $50 \mathrm{\mu m}$ fracture ploticd as 3 function of deplth below the infilusation source. Curves are plotled every 2 hours during the 2 day "acuve" stage of the infiluraton event.

Figure 14. Liquid saturation profile along centerline of a $100 \mathrm{\mu m}$ fracture plotted as a function of depth below the infiturauon source. Curves are ploted every 2 hours during the 2 day "xetive" slage of the infiltratuon erent.

Figure 15. Liquid saluration profile in matrix plotsed normal to a $50 \mathrm{\mu m}$ fracture at the end of the 2 day "isuve" stage of the unfilusauon event. Curves are ploted at depths of 1.5 . and $10 \mathrm{~m}$ below the infiltratuon source. 
Figure 16. Liquid saturation profile in matrix plotied nomal to a $100 \mu \mathrm{m}$ fracture at the end of the 2 day "aclive" stage of the infileration event. Curves are plotted at depths of 7.4. 37, and $74 \mathrm{~m}$ below the infileration sou'ce.

Figure 17. Liquid saiuration profile in matrix plistat normal to a $I(X) \mu m$ fraclure at the end of the 2 day "active" stage of the infiliration event. Curves are plotied at depths of 1,5 , and $10 \mathrm{~m}$ below the infiltralion source.

Figure 18. Liquid saturation profile for $1 \cdot \mathcal{D}$ matrix imbibition normal to a fully saturated houndary. Coarse mesh model uses horizontal grit! spacing of the 2-D fraciure/matnx model.

Figure 19. Imbibition front penctsation deph tno matrix versus bne. Note that distances are measured from the fully salurated boundary.

Figure 20. Log of imbibition front penctration deph into matrix versus log of time. Note that distances are measured from the fully salurated boundary.

Figure 21. Liquid saluration profle along centerline of a $50 \mathrm{\mu m}$ fracturc 0, 2. 4, 12, and 24 hours after the removal of the infiluration source for $\phi_{m}=20 \%$ and $S_{m}=65 \%$.

Figure 22. Liquid saluration profile along centerline of a $100 \mu \mathrm{m}$ fracture $0,2,4,12$, and 2.4 hours after the removal of the infiltuation source for $\phi_{m}=20 \%$ and $S_{m}=65 \%$.

Figure 23. Liquid saturation profile in matrix ploted normal to Iracture face 24 hours after the removal of the infiluation sour:e for $\phi_{m}=20 \%$ and $S_{m}=65 \%$ as predicted by the "coarsc" mesh versions of the two-dimensional fracture/matrix model and the one-dimenstonal matrix imbibition model.

Figure 24. Liquid saturation profile in matrix ploted normal to fraclure face $0,8,58$, and 358 days after the removal of the infiluration source for $\phi_{m}=20 \%$ and $S_{m}=65 \%$.

Figure 25. Normalized bulk saturation versus time within a $7.5 \mathrm{~cm}$ band straddling the frazture for aperiures of 100 and $1000 \mu \mathrm{m} . \phi_{m}=20 \%$, and $S_{m}=65 \%$.

Figure 26. Normalized bulk saturation versus time within a $7.5 \mathrm{~cm}$ band straddling the fracture for apcrures of 100 and $1000 \mu \mathrm{m}, \varphi_{m}=10 \%$, and $S_{m}=82.5 \%$.

Figure 27. Normalized bulk saluration versus tinc withı a $15 \mathrm{~cm}$ radius spherical averaging kemel straddling the fracture for apertures of 100 and $1000 \mu \mathrm{m}, Q_{m}=20 \%$, and $S_{m}=65 \%$.

Figure 28. Normalized bulk soluration versus ume withın a $15 \mathrm{~cm}$ radius spherical averaging kemel stiaddling the fracture for apenures of 100 and $1000 \mu \mathrm{m} . \phi_{m}=10 \%$, and $S_{w 1}=82.5 \%$. 


\section{Introduction}

The Nevada Nuciear Waste Storage Investigations (NNWSi) Project of the U.S. Deparment of Energy (DOE) is investigating the feasibility of constructing and operating a high-leve] nuclear waste repository in tuffaccous rocks occurring in the unsaturated zone at Yucca Mountain, Nevada. The NNWSI project has assigned Lawrence Livermore National Laboratory (LLNL) the task of designing and assessing the expecied performance of waste packages in the repository environment.

The reliable assessmenl of waste package performance requires, among other things, accurate characterization of the thermal and hydmlogic properties of the near field geologic envinonment. Various in situ tests will be conducted in the Exploratory Shaft within the Topopah Spring member of the Paintorush Tuff at Yueca Mountain. The Engineered Barrier Design Test (EBDT) is designed to investigate the rock mass response to the heat load gene-ated by emplaced electrical heaters representing waste packages (Yow, 1985). Prior to conducting the EBDT, prototype "heater" experiments will be carricd out in the G-Tunnel complex of the Deparment of Energy, Nevada Test Site. Nye County, Nevada in a welded ash flow tuff formation of the Grouse Canyon member of the Belted Range tuff as described in Prototype EBDT - Horizontal Emplacement contained in the Nevada Waste Manugenent Program (NWMP) Quality Assurance Program Plan (QAPP) (LLNL. 1987).

A central issue to be addressed during both the prototype "heater" expcriment and the EBDT is the hydrothermal response of the vanably saturated, fraclured rock mass to heating. cocling. and possible future recharge events. Particular interest lics in understanding the role of fractures on fluid movement within the fractured rock mass. The development of validated near freld now and transpon models will (in part) depend on our atbility to spatially resolve, through the use of various gecophysical measurements, the manner in which fraclures influcnce hydrologically and hydrothemally driven changes in the moisture distribution. As described in Prototype EBDT - Horizontal Emplacement contaned in the NWMP QAPP (LLNL, 1987). the eurrent test plan calls for three geophysical techniques for measuring moisture distribution. including alterant geophysical tomography, neutron and gamma (densily) surveys. We will consider twr techniques, geophysical tomography and neuton surveys, because they are 
thought to be more sensitive to the relatively small changes in bulk saturation which will prevail in the vicinity of a fracture undergoins an episodic infiltration event. For the sake of illustration, we will concentrale on geophysical tomography. However. as will be show'n. observations conceming the geotomographic signature of such events also apply to neutson surveys.

The ability of alterant geopinysical tomography to delincate flow paths in fractured. densely welded tiff has been investigated by Ramirez and Daily (1985 and 1987). Their work. which is also described in Daily and Ramires. (1987), has suggested that the anomalies in the tomographic images are related to the flow of witter through tractures. Their omographic images typically consist of arrays of $7.5 \mathrm{~cm} \times 7.5 \mathrm{~cm}$ pixels which are probably two orders of magnitude wider than tise largest fracture apenure of interest. Dut to the courseness of the pixel amays, an image anomaly does not so much reflect flow within if fracture as it reflects matrix imbibition occurring adjacent to the fracture which arises duc to fracture flow.

The primary objectives of this numerical study are to (1) investigate, in detail, the penurbation in the saturation distribution in the vicinity of a fracture undergoing an episodic infiltration event in partially saturated welded tuff which (presumably) give rise to the kinds of image anomalies observed by Ramirez and Daily (1985 and 1987) and (2) average that behavior over volumes thought to be representative of the averagirg kemels inherent to the geophysical techniques of interest. In other words, we will (1) present the details of this episodic infiltration evr $\rightarrow$ at a scalc at which we would ideally be abte to make our measurements, and (2) integrate that behavior over the scale at which moisture measurements are likely to be made. Questions such as those conceming the sensitivily of these measurement techniques (relative to the magnitude of the measured sanges) an beyond the scope of this study and should be addressed in a following study. The averaged results of this siudy should be considered to be qualitatively indicative of the finest detail which can be currently expected of these techniques (provided that all requisites of the considered geophysical method ane adequalely satssfied). Because this sludy is intended to be applicable to both the EBDT al Yucca Moun:ain, ac well as the protolype "heater" experiment in G.Tunncl complex, it was carried out for a range of conditions considered to be representatuve of the fractured welded tuff found in both the Topopah Spring and cirouse ranyon members 
Because of the length of this paper, it is probably worthwhile to briefly consider its organization. In Section 1. we discuss (1) the episodic infiltration event being considered in this study. (2) the geophysical techniques which will be used in situ to observe that event, and (3) how the model calculations will relate to the interpretation of those geophysical measurements. In Section 2, we describe the numerical code used in this study. In Section 3, we discuss the physical data and assumptions required by the numerical models used in this study. The major thrust of this tepon is covered in Section 4, which describes the interaction between fracture flow and the flow in the adjoining matrix, and in Section 5. which estimates how the resulting perurbation to the saluration field may appear to geophysical surveys.

\section{Problem Description}

The hydrothermal bchavior of the ncar field waste package environment will be studied using various measurement techniques (Yow, 1985). Changes in moisture distribution will be monitosed using several different methods including neutron and gamma (density) surveys and alterant geophysical tomography. Because the source and receiver are containcd within the same instrument string. borehole surveys conducted with neutror. and gamma (density) tools only provide an integrated measurement of the moisture distribution within an averaging kernel. If the region within this kemel is homogeneous with respect to rock properties and moisture distribution and if the tool is concentrically located in the borehole, the averaging kernel will be nearly spherical with a radius which is dependent on the moisture content within that kemel. For the prototype "heater" experiment in G-Turinel complex it is estimated that the averaging $\mathrm{kemel}$ for the neuiron tool will have a radius of approximately $15 \mathrm{~cm}$ (Carlson, personal communication, 1988). For the neutron and gamma (density) surveys, spatial definition of the moisture distribution is only available as a function of axial position along the borehole. A potential limitation with these two methods is that the moisture distribution within the averaging kemel may have been significantly perturbed by the drilling fluid and grout used Juning like construction of the cased instrument borehole.

Becausc it is able to make measurements away from the instrument borchole, the tech. mefuc of alicratix geophysucal comography. described in Kamites and Daily (1985 and 1987) and Danly and Ramirez (1987) should nol be adversely affected by moisture penurbations 
arising from the construction of the cased instrument borcholes. This technique involves cross-borchole surveys, typically between holcs oriented in a single plane, thercby providing an approximate two-dimensional perspective of changes in the moislure distribution over a relatively broad region of the fraclured rock mass. By making high frequency clectromagnctic (HFEM) measurements before as well as after the saturation field has been perturbed (the alterant technique). the manner in which the rock influences the signal is subtracted out; differences only reflect changes which have occurred in the moisture distribution. ccause the tomographic images used in their studies consist of arrays of $7.5 \mathrm{~cm} \times 7.5 \mathrm{~cm}$ pixcls (which is perhaps two a Jers of magnitude larger than the largest fracture aperure of relevance), the anomalies seen in their tomographic images lack the resolution to define liquid flow within the fractures as an isolated phenomenon. Moreover, fracture flow in welded luff does not occur as an isolated phenomena. As will be shown, fow within the fractures in welded luff cannot occur without significanly perturing the saturation conditions in the adjoining matrix. Therefore, these image anomalies are a reflection (or signature) of flow phcnomena occurring bout inside and adjacent to the fracture, not just flow within the fractures themselves.

Detailed calculations of fraclure flow in unsaturated welded tuff by Buscheck and Nitao (1988) show that the capillary discontinuity at the fracture/matrix contact results in matrix imbibition occurring adjacent and normal to flow in the fracture. Duc to the very high capillary and adsorptive fores which prevail in the matrix under natjve saturation conditions, the fractures arc essentially drained of the lıquid phase (Wang and Narasimhan, 1985). Later in this repon we will show that liquid water may only reside (and thercby now) in the fractures if the matrix immediately adjoining the fracture is nearly fully saturated. During the onset of an episodic infiltration event, the width of this nearly saturated zone in the adjoining matrix is only of the order of the fracture apenure. If water flow in the fracture persists, matrix imbibition will continue to occur adjacent to the saturated interval of the fracture. nomal to the fracture. It is this combination of fracture flow and matrix imbibition which the tomographic image anomalics noted by Ramires and Daily (1985 and 1987) are actually reflecling. Rather than underaking a comprehensive analysis of the jriteraction between the flow ficlds in the fracture and matrix, as is done in Nitzo and Buscheck (1988), the emphasis of this study is the weting zonc atong a lracture during an spusodtc intiltration event and how that zone appears at the scalc at which geophysical measurenents are likcly to be made 


\section{Modeling Approach}

\subsection{Code Description}

For this investigation all numerical calculations werc carricd out using LLNL's version of the TOUGH code (Nitao, 1988; Buscheck and Nitao, 1987a). The acronym "TOUGH" stands for "transport of unsaturated groundwater and heat". TOUGH is a multidimensional numerical simulator cspable of modeling the coupled transpon of water, vapor, air, heat, and aqueous phase constituents in fractured porous media. It is a member of the Mulkom family of multiphase, multicomponent codes developed at Lawrence Berkeley Laboratory by Preuss (1985). TOUGH has seen previous use in studies of high-level nuclear waste isolation in variably saturated geological media (Preuss, Tsang, and Wang, 1984: Tsang and Preuss, 1986).

The TOUGH simulator accounts for liquid and gaseous phase fluid low under pressure, viscous, and gravity jorces according to Darcy's Law, with interference between phases represented by relative permeability versus saturation curves for the respective phases. The combined effects of capillarity and phase adsorption are accounted for in the suction pressure (or matric potential) veisus saluration curves. These curves are also called moisture retention curves. Vapor pressure lowering due to capillarity is accounted for using Kelvin's equation (Edlefsen and Anderson, 1943). In addition to binary diffusion in the gas phase, there is an option to include the effect of Knudsen diffusion, which is also called the Klinkenberg effect (KJinkenberg, 1941). Hysteresis is not presently accounted for in either the moisture retention or relative permeability curves. An efficient equation-of-state table-look-up algorithm accurately determines the themophysical propertics of liquid water and vapor based on experimentidly derived steam tables (Intemational Committee. 1967). Air is treated as an ideal gas and air dissolution in water is represented by Henry's Law. Heat eranspon mechanisms include conduction, with themal conductivity dependent on water saturation, and convection, including both sensible and latent heat. Hydrodynamic dispersion is not accounted for in the code.

The goveming mass- and energy-balance continuum equations are discretized in space using the "integral finite difference" method (Edwards, 1972; Narasimhan and Witherspoon, 1976). Time is discretized in a fully implicit manner. Due to the strongly coupled, highly 
nonlinear interdependence of mass and heat flow, TOUGh performs a complctely simultancuts solution of the diseretized goveming equations. taking all coupling terms into account. The nonlinearities are handled by Newtor/Raphson iteration and in LLNL's version of TOUGH the solution matrix is inverted using a block banded Gaussian elimination scheme (Nitao, 1988: Buscheck and Nitao, 1987a). Additional details of the TOUGh code can be found in Preuss (1986) and Preuss and others (1985).

\subsection{Upstream Weighting}

For this sludy (and as was done in Buscheck and Nitao, 1987b and 1988) the commonly used, single point, full "upstream weighting" scheme was cmployed to evaluale the mobilitics at the gridblock interfaces. The TOUGH code provides the option of setting the upstream weighting factor WUP where $0 \leq$ WUP $\leq 1$. As will be shown later, because there is lituc capillary diffusion within the fracture, the infiltration pulse moves down the fracture as a sharp displacement front. Flease note that we anc only considering vertical fractures. Consequently, the liquid relative permeability varies considerably over a relatively shon distance along the fracture. This sharp gradicnt in liquid relative permeability makes the choice of weighting scheme in evaluating the interblock mobilities quite critical.

There has been some debale over the appropriatc choice of the upstrean weighting factor in modeling an infiltuation pulse down an initially unsaturated fracture. The experience of those in the petroleum reservoir simulation field is useful in determining the appropriate weighting schemc. It should be recognized that this problem of liquid water displacing air in a fracture is quile similar to the well-known Buckley-Leverett one-dimensional immiscible displacement problem (Buckley and Leverell, 1942: Dake, 1978). For the Bucklcy-Lcverett problem, Aziz and Sctiari (1979) evaluated the accuracy of several different weighting schemes (including midpoint weighting, onc-and two-point upstream weighting) against analytical solutions. They evaluated the midpoint weighting scheme for several different grid densities and found that as the grid spacing is refined, the numerical solution converges to a different, unreal solution. In other words, while midpoint weighting converges to a solution which is mathematically possible, it is physically invalid. In comparing the numerical solutions which employed the onc- and two-point upstream weighting schemes to the analytical solution, they 
found that both numerical solutions converged to the correct answer. However, the secondorder upstream formula gave a sharper displacement front than the single-point formula.

Because the second-order upstrean formula is not an option with LLNL's version of the TOUGH code and because it requires so much computer time, we decided to employ the standard onc-point formula racher than modify the code to handle the two-point formula. As is covered in sutsection 3.5, the impact of gerd spacing on numerical diffusion of the infiltration front in the fracture was evaluated. For the range of grid spacings cvaluated, it was found that the results are essentially mesh independent. Therefore, the single-point upstream weighting formula, in combination with the grid densities which were used, appear to adequately handle the tracking of the infiltration front for the problems we considered.

\section{Discussion of Physical Data and Assumptions}

\subsection{Mal rix Properties}

The calculations carried out in this study require a number of assumptions regarding the relevant hydrologic properties, initial and boundary conditions. For the Grouse Canyon denscly welded tuff found in G-Tunnel. Zimmerman and Blanford (1985) reported an initial saturation greater than 60 percent and a matrix porosity ranging from 15 to 46 percent. For a simple laboratory imbibition experiment Buscheck and Nitao (1987b) reponed a matrix porosity $\phi_{m}=8.4$ percent for a sample of Grouse Canyon densely welded tuff taken from GTunnel. For sample G4-6 which was a sample of Topopah Spring tuff cored at a depth of 1158 fect within the repository interval at Yucca Mountain, Peters and others (1984) obtaincd $\phi_{m}=11$ percent. The initial saturation of Topopah Spring tuff has not becn measured in situ at the repository horizon at Yucea Mountain. Estimates have been made based on various assumed steady-state infiltration rates. For an assumed infiltration rate of $0.1 \mathrm{~mm} / \mathrm{yr}$, Wang iid Narasimhan (1986) obtain an initial saturation $S_{m i}=80$ percent. For the same assumed infiltration rate, Nitao (1988) calculated $S_{m i}=85.4$ percent. In order to cover the range of porosities and saturations considered possible for both Grouse Canyon tuff found in G-Tunnel and Topopah Spring tuff found at the repository horizon at Yucca Mountain, we repeated our calculations for $\phi_{m}=10$ and 20 percent and for $S_{w i}=65,82.5$, and 85 percent. 
There are no published data for the characteristic curves (relative permeability and suction pressure versus saluration) for Grouse Canyon densely welded uff. The on!'g availabie dala for absolute matrix permeability $k_{m}$ were measured with arr (Board, et al., 1987). Because no attempt was made to isolate the effect of Kuudsen diffusion (slip flow) in their measurements, their values for $k_{m}$ are likely to be greater than values which would have been obtained widh water. Russo and Reda (1987) repon that the cffect of Knudsen diffusion can result in $k_{m}$ measured with gas being an order of magnitude greater than $k_{m}$ measured with water. Bectasc our calculations are much mure sensitive to liquid phase (han gas phase) permesbility. We decided that the gas-measured $k_{m}$ data of Board and others (1987) is not applicable.

Zimmerman and others (1984) determined that the welded tuffs in G-Tunnet have similar bulk. thermas, and mechanical properties to those of Topopill Spring welded tuff found in the repository horizon at Yucea Mountain. Accordingly, we decided to use the absolute matrix permeability and characteristic curve data obtained by Peters and others (1984) for the Topopih Spring sample G4-6 in all of our calculations. They abtained their matrix moisture retention curves by applying the curve-fitung method developed by van Genuchten (1980) 60 their moisture retention data. Their matrix relative permeability curves were not determined direcly from experimental data. Instead, Peters and others (1984) derived their relative pe meability curves from their moisture retention curves using the theoretical method of Mualem (1976). While Peters and others (1984) express their characteristic curves as functions of suction pressure, TOUGH requires that they be expressed in terms of saturation (Figures 1 and 2).

It is important to recognize how Peters and others (1984) obtained their moisture retention data. Staning with a fully saturated simple. they desaturaled it in small incremental steps by placing it in a microwave oven for 30 seconds, removing and allowing the sample to cool before weighing it and measuring the suction pressure with a thermocouple psychrometer. Microwave heating enabled the samples to be dried more uniformly than drying in a conventional thermal oven. Assuming that the mass of pore vapor which re-condenses during cooling is negligible in comparison with that which leaves the sample, this is effectively a drainage process. Because dala was not obtained under imbibition conditions, it is nol possible to construct hysteretic moisture retention curves which ipply to imbibition as well as drainage. 
Due to the absence of moisture retention data for imbibition conditions, Buscheck and Nitao (1987b) initially attempted to model their imbibition experiment using the G4-6 moisture retenuon curve which was obtained by Peters and others (1984) for drainage conditions. The lack of agreement between the observed and calculated results was attributed primarily to a combination of two different causes: (1) uncenainty conceming $k_{m}$ of the sample and (2) uncentainty conceming the appropriateness of the drainage curve in modeling an imbibition process. They devised a simple means of effectivcly accounting for the net effect of these uncertainties. Because the calculations contained in this report require valid imbibition data, we have included the highlights (as well as a $\mathfrak{x}$-examination) of their observations and analysis in the following subsection.

\subsection{The Efrect of Hysteresis on Moisture Retention}

The effect of hysteresis of moisture retention curves has received considerable treatment in the fields of soil physics (Hillel, 1982: Marshall and Holmes, 1981) and reservoir engineering (Dake, 1978). Figure 3 (taken from Bcar, 1979) depicts a typical hysterctic moisture retention curve. A notable feature is that the boundary drainage curve and the boundary imbibition curve envelope a family of scanning curves from above and below, respectively. If a process involves either monotonic drainage (starting from salurated conditions) or imbibition (starting from imeducible saturation), then the process will follow one of these boundary curves. The net effect of hysteresis on moisture retention is that for a given suction pressure, the liquid saturation is greater during drainage than it is during imbibition. If the assumption is made that within the saturation range of interest the semi-log plot of the imbibition and drainage moisture retention curves ane parallel, then for a given saturation. the ratio of the imbibition and drainage suction pressures is a constan which we will call the hysteresis factor $\lambda$. Therefore, during imbibition the prevailing suction pressures are simply those given by the drainage curve multiplicd by $\lambda$ where $0<\lambda<1$. For a laboratory imbibition experiment on an intact sample of Grouse Canyon densely welded tuff (i.e. matrix only), Buscheck and Nitao (1987b) found that applying $\lambda=0.025$ to their model resulted in very good agrecment between calculated anı observed resaturation data for a range in matrix buik saturation of 47 to 89 percent. 
Figure 4 is a hypothetical extrapolation of the resaturation data observed by Buset sek $^{2}$ and Nitao (1987b). Provided that the drainage curve obtained by Peters and others (1984) for sample G4-6 is applicable to the sample used in the matrix imbibition experiment descrebed in Buscheck and Nitao (1987b), this curve honors their observed imbibition data for the $\mathrm{r}$ nge in matrix bulk saturation of 47 to 89 percent. Because they did not oblain resaluration data for saturations less than 47 percent and because Peters and others (1984, did not oblain suction pressures for saturations less than approximatcly 5 percent, we decided (for the sake of illustra. Lion) to depict Figure 4 with an irreducible saturation of 1 percent. It should he noted that the imbibition calculations made herein only depend on the matrix moisture retention data in the range of 65 to 100 percent bulk saturation. As will be argued later, it is likely that for the timespan being considered in this study ( $\leq 48$ hours), thai the upper bound in bulk saturation for relevant matrix imbibition data is less than 90 percent.

Although it was not reponed, the approximation of taking $\lambda$ to be constant for all salurdtions resulted in Buscheck and Nitao (1987b) overpredicting the rate of imbibition in the saturation range of 89 to 100 percem. After 24 hours of matrix imbibition. while the bulk saturation of the sample was observed to be only 92 percent, the model calculated a bulk saturation of 100 perceni. Because the sample had only reached 94 percent saturation after 6 days of imbibition at atmospheric pressure, it was decided to place the sample in a pressure vessel. After two additional days of imbibition under a pressure of 110 psig. the sample finally appeared to be fully saturated. This lag in the observed irrbibition rate (as companed to the model which assumed a constant $\lambda$ for all saturations) is strongly indicative of the entrapped air effect illustrated in Figure 3. If the entrapped air effect is accounted for, Figure 4 would be replotted approximately as shown in Figure 5 with the imbibition curve steeply declining in the range of 90 to 92 percent saluration with the slope approaching negative infinity as 92 percent saturation is approached. In doing this, we have allowed $\lambda$ to be a variable and have taken the entrapped air saturation value to be $n=8$ percent. The increase in matrix bulk saturation between 92 and 100 percent saturation occurs only as enirapped air is dissolved in water and is transponed in the licquid phase as a result of molccular diffusion. 
As noted above. the use of a constant $\lambda$ is only rigorously correct in an intermediale range of saluration where the semi-log plot of the drainage and imbibition curves are parallel to each other. For the matrix imbibition experiment described in Buscheck and Nitao (1987b) that range where $\lambda$ can be taken to 'oe a constant was observed to at Ieast span the 47 to 89 percent range in bulk saturation of the sample. It may be argued that although the sample may not have reached fuli bulk saturation, the outer several millimeters of the sample did reach full saturation, thereby violating the applicability of a constant $\lambda$ for the outer region of the model. However, assuming a constant $\lambda$ resulted in their model agrecing closely with the observed imbibition rate for the first eight hours of the experiment even though the outer few millimeters of the sample had reached full saturation. Apparently, the relevant measure of saturation in detcrmining the range of applicability of a constant $\lambda$ for this matrix imbibition experiment is the bulk saluration of the sample, not the local saturation determined for small subdomains $\delta r \leq$ $1 \mathrm{~mm}$ (recall that the Grouse Canyon welded iuff sample was a cylindrical core $2.52 \mathrm{~cm}$ in diameter). The following is an argument why the range of matrix bulk saturation for which the constanı $\lambda$ was calibrated (47 to 89 percent) is applicable to the calculations reponed herein.

As can be seen in Figure 17 (which will be discussed in detail in later sections), for the timeframe under consideration in this study ( $\leq 48$ hours), the imbibition front penetration (normal to the fracture) is calculated to be as much as $2 \mathrm{~cm}$. Note that this penetration depth is measured from the plane of symmetry of what is idealized to be a symmetrical periodic fracture within an infinite array of uniformly spaced, parallel vertical fractures. For the most extreme case plotted in Figure 17, the total width of the imbibition zone about the fracture (including both sides of the fracture) is $2 \times 2 \mathrm{~cm}=4 \mathrm{~cm}$. By evaluating the data of Sinnock and others (1985) and Thodarson (1983), Wang and Narasimhan (1985) obwined fracture spacings of 0.22 and $0.48 \mathrm{~m}$ for verical and horizontal fractures, respectively. Therefore, if we consider the bulk saturation of the matrix adjacent the fracture to be that averaged over a 0.11 $m$ half-interval between neighboring parallel vertical fractures, we can calculate the change in matrix bulk saturation over that half-interval. For an initial saturation of 65 percent and an imbibition penetration depth of $2 \mathrm{~cm}$, the net increase in bulk saturation of the matrix calculated over the half-interval between neighboring fractures is 6 percent. resulting in a final bulk saturation of 71 percent. Note that this falls within the range in bulk saturation for which the use of a constani $\lambda$ resulted in good agreement between the calculated and observed matrix 
imbibition data described in Buscheck and Nitao (1987b).

For the sake of argument, we can consider the position which asserts that the relcvant saturation range for the matrix moisture retention data (necessarily) spans 6510100 percent (instead of 65 to 89 percent) for these calculations. Based on this premise, we would have to conclude that the use of a constant $\lambda$ will result in the model overpredicting the rate of matrix imoibition normal to the wetted fracture over the 89 to 100 percent range in matrix saturation (relative to that observed experimentally). This altemative position is equivalent to saying that, although a constant $\lambda$ was found to accurately represent matrix imbibition in the laboratory sample for a range in matrix bulk saturation of 47 to 89 percent. we are still concemed that (for small subdomains in the matrix adjacent to the fracture) the local saluration exceds 89 percent. This position maintains that for these small regions, the rate of matrix imbibition will be overpredicted relative to that which would be obscrved experimentally. Recall that this overprediction is due to a constant $\lambda$ not accounting for the air entrapment effect noted earlier. The outcome of this altemative position (that the relevant range in saturation data spans 65 to 100 percent) is that all calculations reported herein would be considered as upper bound estimates of the rate of matrix imbibition.

Because Buscheck and Nitao (1987b) did not repeat their imbibition experiment for a sample of Topopah Spring densely welded tuff and due to the similarities noted by Zimmerman and others (1984) between Grouse Canyon and Topopah Spring densely welded tuff, we decided to apply $\lambda=0.025$ (which was determined for Grouse Canyon welded tuff) to all of the calculations made in this study. The implied assumption is that Grouse Canyon and Topopah Spring densely welded tuff exhibit similar hysteretic behavior.

\subsection{Fracture Properties}

For intact fractured samples of Topopah Spring welded tuff (i.e. core samples which have not separated along fractures), Klavetter and Peters (1985) measured a range of fracture apertures of 4.34 to $5.13 \mu \mathrm{m}$. Because core samples typically separate in the core barrel along the larger apenure fractures, intact samples tend only to reflect small aperture fractures. thereby biasing out large aperture fractures. Wang and Narasimhan (1985) derived fracture apcrture 
parameters and discrete fracture perneabilities from estimated bulk rock salurated perneabilitics reponed by Thodarson (1983) and Sinnock, Lin, and Brannen (1984). For Topopah Spring welded tuff they obtained an effective hydraulic apenure of 116 and $150 \mu \mathrm{m}$ and a discrete

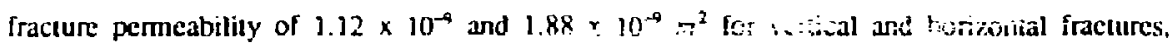
respectively. They also obtained fracture spacings of 0.22 and $0.48 \mathrm{~m}$ for vertical and horizontal (metures, respectively. Zimmerman and Finlcy (1987) assumed the validity of the cubic law for fracture flow in analyzing their water injection data in densely welded Grouse Canyon tuff. From their analysis they obained a mean fracture aperure of $90 \mu \mathrm{m}$ with a standard deviation of $59 \mu \mathrm{m}$. Buscheck and Nitao (1988) considered fracture apenures of $5010100 \mu \mathrm{m}$ and discretc saturated fracture permeabilities of $8.3 \times 10^{-11}$ to $1.7 \times 10^{-4} \mathrm{~m}^{2}$.

Figure 6 is the relative permeability curve used to model both the 50 and $100 \mathrm{\mu m}$ fracture. It shouid be noted that there is no physical data upon which to base the characteristic curves in the fractures. The fracture relative permeability curve was estimated by Wang and Narasimhan (1986) based on a simple conceptual model of fraciure flow. Please note that unless otherwise indicated, the fracture apenures quoted herein are cffective hydraulic apertures as given by the cubic law. Applying the cubic lav to fracture apenures of 50 and $100 \mu \mathrm{m}$ we obtain discrele salurated fracture permeabilities of $2.1 \times 10^{-10}$ and $8.3 \times 10^{-10} \mathrm{~m}^{2}$, respectively. Although not necessarily rigorously correct, for this study effective hydraulic apertures and volumetric apenures ane assumed to be equal.

Evidence exists (Neretnicks. 1985) that hydraulic apenures deduced from permeability measurements can be one or two orders of magnitudie smaller than "volumetric" apertures derived from the residence time of tracer transpon measurements. Buscheck and Nitao (1988) considered cases in which the hydraulic and volumetric apenures are not cepual. When considering the geophysical signalure of the apparent width of the wetting zone (using either a 7.5 cm $\times 7.5 \mathrm{~cm}$ pixel or a spherical averaging kemel having a radius of $15 \mathrm{~cm}$ ) the variable of inlerest is the change in the nomalized bulk saluration $S_{\text {eb }}$ within that averaging volume. In Equation 9 (subsection 5.2) we sce that $S_{\text {eb }}$ takes into account the saturation conditions within the fracture as well as the matrix. Conscquenty, we find that the volumetric fracture apenure affects the geophysical signature of the apparent width of the wetting rone. 
Figures 7 and 8 are fracture moisture retention curves under drainage conditions for fracture apenures of 50 and $100 \mu \mathrm{m}$, respectively. These curves were cxirapolitted, using the Young-Lapla. e equation (Adamson, 1982). from a fracturc moisture retention curve which was; estimated by Wang and Narasimhan (1986) based on a simple conceptual model of fracture flow. Because there is essentially no physical dala for fracture rnoisture retention curves as wcll as no physicai data from which to infer a value of $\lambda$ for fractures in denscly welded tuff, we decided to leave $\lambda=1$ (assuming no hysenesis) for the fractures. Moreover, because the suction pressures seen in Figures 7 and 8 are so small (absolute values generally being less than atmospheric) the impact of setting $\lambda<1$ for the fracture is negligible.

\subsection{Boundary Conditions}

For this study we considered a semi-infinite fracture with periodic boundaries. The implied assumption is that all fractures are verical and parallel to each other with a uniform spacing of $0.5 \mathrm{~m}$. Note that this assumed fracture spacing differs somewhit from that determined by Wang and Narasimhan (1985). As will be seen in the following section, for the timeframe considered in this study ( $r \leq 48$ hours) there is no interference between neighboring fractures. In other words, the penetration of the imbibition front normal to the direction of fracture flow is very small relative to the half-distance between neighboring fractures. Because the saturation fields of neighboring fractures do not interfere, they effectively behave as though they occur within an infinite horizontal domain. Even for a fracture spacing of $0.22 \mathrm{~m}$ it is found that neighboring fractures do not interfere. Consequently, within the range of fracture spacings considered relevant for Topopah Spring and Grouse Canyon welded tuff, the calculations reported herein ane not sensitive to fracture spacing. The periodic boundaries are employed pardy as a convenience so that symmetry could be taken advantage of in constructing the numerical mesh. Two planes of symmetry then exist: (1) the plane of symmetry down the center of the fracture and (2) the midplane between neighboring fractures. In the numerical mesh both planes are treated as impermcable boundaries.

The source of the episodic infiltration pulse is a very large computational boundary block connected to the uppermost fracture block. The boundarv block serves as a constant pressure and saturation boundary. Al $1=0$ hours the infittration event is begun by setuing the saturation 
of this boundary block to 100 pereent and its pressure to one atmosphere for the duration of the "active" stage of the event $(0 \leq t \leq 48$ hours). The infiltration front then propagates down the fracture under a unit gravity gradient for the duration of the "active" stage. At $1=48$ hours the "active" stage is stopped by setting the saturation of the boundary block to zero.

A physical example relevant to these assumptions and boundary conditions is the unrealistic case of an infinitely long, horizontal borchole which is drilled parallel to the infinitcly long fracture which it intersects. Water then fills the borehole for a given period of time. Because the borehole is not inclined and its water not pressurized (and becausc the hydrostatic head of water over the diameter of the borchole is negligible), watcr in the borchole is considered to be fixed at one atmosphere of pressure. For this example to be rigorously cornect, each fracture of this infinite array would be intersected by a parallel bonchole which is continuously filled with water at atmospheric pressure. For the timcframe considered in this study, it will be shown that the fractures do not interfere. Consequendy, our system can be considered to be a single fracture with infinite spacing.

\subsection{Numerical Grid}

Table 1 lists the two-dimensional grid spacing used to represent a fracture having an aperture of $100 \mu \mathrm{m}$ and a saturated discrete fracture permeability of $8.33 \times 10^{-10} \mathrm{~m}^{2}$. Note the constant grid spacing used in the vertical direction. In order to accurately model matrix imbibition adjacent (and nomal) to the fracture it was necessary to employ very small horizontal grid spacing close to the fracture. The vertical grid spacing was chosen in orter to minimize numerical dispersion while at the same time kecping the computational costs within reasonable limits. A mesh sensitivity study was conducted in order to evaluate any mesh dependence in the calculations. A comparison of three numerical meshes (one more refincd and one coarser than the mesh listed in Table 1) indicated that the results were essentially independent of the choice of mesh. Table 2 lists the two-dimensional grid spacing used to represent a fracture having an aperture of $50 \mu \mathrm{m}$ and a saturated discrete fracture permeability of $2.083 \times 10^{-10} \mathrm{~m}^{2}$. 


\section{Model Results}

\subsection{Two-Dimensional Model of Fracture Flow and Matrix Imbibition}

Figures 9 and 10 are contour plots of the liquid saturation distribution of the wetting $x$ nnc atound a verical fracture at the end of the "active" I wo day stage of an intiltration cvent for a 50 and $100 \mu \mathrm{m}$ fracture, respectively. Note that the contour plots are mated 90 degrees counterelockwise, orienting the fracture midplane along the abscissa. The top of the fracture is found at the lower left comer of Figures 9 and 10 and the gravity vector 1 s oriented horizontally from left to right. Distances in the longitudinal direction (i.c. parallel to the fracture) are measured from the top of the fracture. Distances transverse to the fracture are measured from the fracture midplane. Notice that the ratio of the longindinal sialles for these two cases is 7. As will be discussed later in this section, this longitudinal scaling ratio has very imponant physical significance. Because matrix imbibition transverse to the fracture occurs on a much smaller scale than longitudinal flow along the fracture, it was necessary to exaggerate the transverse scale nelative to the longitudinal scalc. Becausc we wanted to use the same transverse scale in both cases, we have exaggerated the transverse scale by factors of 143 and 1000 for the 50 and $100 \mu \mathrm{m}$ fracture, respectively. For both cases the matrix porosity and initial saturation are 20 and 65 percent, respectively. The shap contrast in the moisture retention curves for the fracture and matrix result in the initial fracture saturation being zero.

Several observations can be made about Figures 9 and 10. First, with appropriatcly chosen longitudinal scaling. the saturation distributions for these two cases are nearly identical. Notice that the lateral extent of matrix imbibition is the same for these two cases. It is apparent that the tongimdinal extent of the welting zone is a very strong function of fracture aperture. Also note that the width of the wetting zone does not change appreciably with (longitudinal) depth for the upper two-thirds of the wetting zone. For the lower third of the wetting zone, the widih of the wetting zone decreases significantly with depth.

While Figures 9 and 10 are "snapshots" of the wetting zonc saturation distribution at the end of the "active" stage, Figures 11 and 12 track the movement of the wetting zone with 
respect to time by plotting the location of the matrix imbibition front on a two hour interval for the duration of the "active" stage. This is done by plotting the location of the 82.5 percent matrix saturation contous which is the mean saturation between the initial and fully saturated conditions. Note that the same longitudinal and transverse scales are applied in Figures 9 and 11 (as well as in Figures 10 and 12). Figures 13 and 14 are plots of the liquid saturation profile along the fracture centerline for the same two cases. Again. the same longitudinal scales are applied in Figures 9, 11, and 13 (as well as in Figures 10. 12, and 14) and the saturation profiles are plotted on a two hour interval for the duration of the "active" stage. Because Figures 11 and 13 (as well as Figures 12 and 14) are plotted with the same longitudinal scale, it is possible to relate the fracture saturation profile to the saturation distribution in the matrix. We can sec by comparing Figures 11 and 13 (as well as Figures 12 and 14) that the wetting zone in the malrix moves at the same longitudinal velocity as the infiltration front in the fracture.

For this report we define the infiltration front penetration depth $h$ to be the longitudinal distance from the top of the fracture to the point where the fracture sanuation is 50 percent In Figures 13 and 14 we observe that $h=13$ and $96 \mathrm{~m}$ at $t=48$ hours for the 50 and $100 \mu \mathrm{m}$ cases, respectively. Therefore, increasing the fracture aperture $b$ by a factor of two results in a 7.4 fold increasc in $h$. Recall that this is essentially the longindinal scaling ratio we used in ploting (and comparing) the saturation ficlds for the respective cases. In the asymptotic expansion solution of a closely related fracture/matrix flow problem (Nitao and Buscheck, 1988), the first order term for $h$ is proportional to $b^{3}$, thereby giving us a scaling factor of 8 between these two cases. Inclusion of the sccond order term in the expansion (which is negative and proportional to $b^{2}$ ) reduces the scaling factor to somewhat less than 8 . Therefore, the observed 7.4 fold increase in $h$ which resulted from a twofold increase in $b$ is corroborated by the theory of Nitao and Buscheck (1988).

We can also make several observations conceming the saturation discontinuity across the fracture/matrix interface. In Figure 9 it is found that the 95 percent matrix saturation contour intersects the fracture at a depth of $13.27 \mathrm{~m}$ where it is also found in Figure 13 that the saturation in the fracture is 36 percent. In Figure 10 it can be seen that the 95 percent matrix 
saturation contour intersects the fracture at a depth of $97.5 \mathrm{~m}$ where it is also found in Figure 14 that the fracture saturation is $\mathbf{4 2}$ percent. In Figure 4 we find that for a matrix saturation of 95 percent. the sucijon head is approximately $50 \mathrm{~m}$ (which is equivalent to a suction pressurc $p_{c}=5 \mathrm{~atm}$ ). From Figures 7 and $8 \mathrm{wc}$ find that $p_{c}=5 \mathrm{~atm}$ corresponds to a zero fracturc sanuration for both the 50 and $100 \mu \mathrm{m}$ fracturs. However, we observed fracture saturations of 36 and 42 percent immediately adjacent to a matrix saturation of 95 percent for the 50 and 100 $\mu m$ cases, respectively. Apparently, while the wetting zone in the matrix moves at the same longitudinal velocity as the infiltration front in the fracture, it also lags the fracture front. In the analytical solution for large time, Nitao and Buscheck (1988) found that the wetting zone in the matrix lags the fracture front by a fixed amount.

Figures 15 and 16 are plots of the liquid saturation profile in the matrix. transverse to the fracture for the 50 and $100 \mu \mathrm{m}$ fracture cases. Saturation profiles are provided at scveral different longitudinal locations along the fracture. The observation conceming the 7.4 fold increase in $h$ between the 50 and $100 \mu m$ fracture cases can be used in companing Figures 15 and 16. In Figure 15, the saturation profile in the matrix nomal to the $50 \mu \mathrm{m}$ fracture was ploted at several arbitrarily chosen depths: $z=1,5$, and $10 \mathrm{~m}$. Note the dependence of the wetting zone width on depth. In selecting the depths to plot the matrix saturation profile transverse to the $100 \mu \mathrm{m}$ fracture (Figure 16), it was decided to apply the scaling factor of 7.4 to the depths used in Figure 15. Accordingly, depths of 7.4, 37, and $74 \mathrm{~m}$ were selected for the $100 \mu \mathrm{m}$ fracturc. When Figures 15 and 16 are superimposed on each other, their respective profiles almost exactly coincide for the three pairs of depths. This suppons the observation that the wetting zone saluration distributions for the two cascs are scaled relative to cach by a longitudinal scaling factor which is roughly proportional to $b^{3}$.

\subsection{The Applicability of the One-Dimensional Model of Matrix Imbibition}

As will be shown, the wetting zone width is controlled by the matrix properties which govem matrix imbibition. Because relevant matrix propeny data for welded tuff is spare and therefore subject to uncertainty, we felt it was necessary to consider the parameter sensitivity of malrix imbibition. The use of a one-dimensional malrix imbibition model would, by vinue of its cconomy, expedite carrying out a matrix parameter sensitivity study. From the saluration 
contours plotted in Figures 9 and 10 we can see that for much of the wetted interval of the fracture, the width of the wetting zone does not vary appreciahly with depth. Therefore, it was felt that a one-dimensional matrix imbibition model provides a reasonably good approximation of the wetling zone width, patticularly as it is "seen" by gecphysical surveys.

For the $100 \mu \mathrm{m}$ fracture (Figure 17) the matrix saturation profile, transverse to the fracture, is plotted at $t=2$ days for three depths which fall within the region of interest for the in situ experiments $(z=1,5$, and $10 \mathrm{~m})$. Note that these three profiles were obtained from the two-dimensional model. Also plotted in Figure 17 is the profile predicted by the onedimensional matrix imbibition model wherein the interface with the fracture is represented by a computational boundary block maintained at atmospheric pressure and 100 percent saturation for all time. In order to preclude any mesh dependency in comparing the matrix saturation profiles calculated by the one- and two-dimensional models, it was necessary to use the same horizontal grid spacing in the respective models (Table 1). As can be seen in Figure 17, for depths of $2=1,5$, and $10 \mathrm{~m}$, the matrix saturation profile, transverse to the fracture, is indiscemible from that predicted by the one-dimensional matrix imbibition model. This implies that we can neglect the finite length of time it takes the slug in the fracture to reach a given lateral slice of the matrix along the $100 \mu \mathrm{m}$ fracture to a depth of $z=10 \mathrm{~m}$ which is within the domain of interest for the EBDT and prototype "heater" experiments. If we superimpose Figures 15 and 17, we find that the sne-dimensional model is also applicable to the $50 \mu \mathrm{m}$ fracture case for $z \leq 5 \mathrm{~m}$. However, at $z=10 \mathrm{~m}$ we observe less imbibition transverse to the fracture in the $50 \mu \mathrm{m}$ case than is predicted by the one-dimensional matrix imbibition model.

Due to large amount of computer time required to carty out the two-dimensional calculalions, it was necessary 10 employ somewhat coarse grid spacing in the horizontal direction (see Tables 1 and 2). In order to investigate the mesh sensitivity of the horizontal matrix imbibition calculations, we compared the results of a one-dimensional matrix imbibition model employing cxtremely fine grid spacing (Table 3) with those of the one-dimensional matrix imbibition model employing the "coarse" horizontal grid spacing of the two-dimensions! models (Tables 1 and 2). Figure 18 is a comparison of the matrix saturation profiles at $t=2$ days calculated by the respective one-dimensional models. Notice that the the results obtained from the coarse 
mesh exhibit a minor amount of numerical dispersion. Relative to the uncertainties inherent to the physical data and assumptions used in these models, the impact of numerical dispersion in the coarse mesh models is negligible.

\subsection{Parameter Sensitivity of Matrix Imbibition}

Figuse 19 is a plot of the imbibition front penetration depth $d_{\text {imb }}$ into the matix as a function of time. For this report, we define the imbitition front penetration depth $d_{i m b}$ to be the distance from the fracture midplane to where the nomalized matrix saturation $S_{e}=50$ percent (see Equation 3 for definition of $S_{e}$ ). Note that by symmetry, the width of the wetting zone about the fracture is twice $d_{i m b}$. The four cases ploned in Figure 19 include wo values of $\phi_{m}\left(\phi_{m}=10 \ldots 420\right.$ percent) and two values of $3_{m}\left(S_{m}=0\right.$ utu 82.5 percent $)$. It can be observed that $d_{i m b}$ decreases as some function of the matrix porosity and increases as some function of the initial matrix saturation

$$
d_{i m b} \sim \frac{f\left(S_{m i}\right)}{g\left(\phi_{m}\right)}
$$

The functional relationship between $d_{\mathrm{kms}}$ and the rclevant matrix pmperies becomes clearer if we replot Figure 19 using a $\log -\log$ scale as is done in Figure 20. Notice in Figure 20 that the plots for these four cases are all parallel with a positive slope of 0.5 . The differential equation goveming mass conservation for this imbibition process is:

$$
\phi_{m}\left(1-S_{m i}\right) \frac{\partial S_{e}}{\partial l}=\nabla \frac{k_{m} k_{m}}{\mu_{w}} \nabla P_{c}
$$

where $k_{m} \equiv$ the liquid relative of the matrix and $k_{m} \equiv$ the absolute matrix permeability, $P_{c}$ is the matrix suction pressure and the normalized saturation is given by:

$$
S_{i}=\frac{S_{w}-S_{w i}}{i-S_{m i}}
$$

with the boundary conditions

$$
S_{s}(x=0)=1 \text { and } S_{e}(x=\infty)=0
$$

Although the general analytic solutions to Equation 2 ase not known, it is known (Boltzmann, 1894) that the solution $S_{*}(x, 1)$ is of the form:

$$
S_{c}(x, l)=f\left(x t^{-1 / 2}\right)
$$


For the function $f(x, l)$ we can elaborate on the general form of its functional dependencies:

$$
S_{c}(x, t)=f\left[x\left[\frac{k_{m} l}{\phi_{m}}\right]^{-1 / 2} ; S_{w i}\right]
$$

where the functional dependency of $f\left(x, t ; S_{w i}\right)$ on $S_{w i}$ arises due to the dependence of the imbibition front mobility $M o b_{i m b}$ on $S_{w}$

$$
\operatorname{Mob}_{\mathrm{imb}}\left(S_{w}\right) \sim k_{m w}\left(S_{w}\right) P_{c}^{\prime}\left(S_{w}\right)
$$

where $P_{c}{ }^{\prime}$ m the derivative of $P_{c}$ with respect to $S_{w}$. The imbibition front mobility is sensitive to the saturation range over which imbibition is occurring $S_{m i}<S_{w}<1$. Because we have set the upstream boundary condition $S_{w}(x=0)=1$, the saturation dependence of the imbibition front mobility is resuricted to $S_{m i}$ as indicated in Equation 5. Because $k_{m w}\left(S_{w}\right)$ is a stronger function of $S_{w}$ than is $P_{c}{ }^{\prime}\left(S_{w}\right), M o b_{i m b}\left(S_{w}\right)$ increases with $S_{w}$. In other words, for increasing $S_{w}$. $k_{r w}$ of the matrix increases more rapidly than the decrease in $P_{c}$ :

It will be recognized that the scaling relationship between $x$ and $t^{-1 / 2}$ seen in Equation 4 and $\mathbf{5}$ is typical of many diffusive phenomena. Because of this functional relationship, the plot of $\log d_{i m b}$ versus $\log \iota$ has a positive slope of 0.5 . The functional dependencies of $d_{i m b}$, which are seen in Figure 20, are summarized in Equations 5 and 6. The dependence of $d_{\text {imb }}$ on $\phi_{m}$ can be observed in Figure 20 by: (1) comparing cases 1 and 3 (for which $S_{m i}=82.5$ percent) and (2) comparing cases 2 and 4 (for which $S_{m i}=65$ percent). For both pairs of cases we considered $\phi_{m}=10$ and 20 percent, thereby varying $\phi_{m}$ by a factor of two. Notice that for both pairs of cases, increasing $\phi_{m}$ by a factor of two has the effect of posilively shifting time (log $d_{i m b}$ versus $\log t$ curve is shifted to the right) by approximately $0.3 \log$ cycles (which is = $\log 2$ ). This $\phi_{m}$ dependent positive shift in time follows from

$$
x \sim\left(\frac{k_{m} l}{\phi_{m}}\right)^{1 / 2}
$$

which wc get from Equation 5. We can now claboratc on the expression for $d_{i m b}$

$$
d_{i m b} \sim \frac{f\left(S_{\mathrm{wi}}\right)}{\phi_{m}^{1 / 2}}
$$


The dependence of $d_{i r b}$ on $S_{w i}$ (which is related to $\operatorname{Mob}_{\mathrm{mb}}\left(S_{w}\right)$ ) can be observed in Figure 20 by: (1) comparing caces 1 and 2 (for which $\phi_{m}=10$ perccnt) and (2) comparing cases 3 and 4 (for which $\phi_{m}=20$ percent). For both pairs of cases wc considered $S_{m}=65$ and 82.5 percent. For both pairs of cases. increasing $S_{m}$ from 65 to 82.5 percent results in a negative time shift of $0.17 \mathrm{log}$ cycles. This negative time shift (i.c. shifling the curve to the teft) ariscs due to the $\operatorname{Mob}_{\mathrm{imb}}\left(S_{w}\right)$ dependence or $S_{w+}$. As mentioned earlicr, because $k_{m u}\left(S_{w}\right)$ is a stronger function of saturation than is $\boldsymbol{P}_{r}\left(S_{w}\right), M o b_{i m b}\left(S_{m}\right)$ increases with increasing $S_{m}$. Consequently, increasing $S_{w i}$ causes a $M o b_{i m b}\left(S_{w}\right)$ related negative time shift. Similarly, it can be scen in Equations 5 and 6 that increasing $k_{m}$ also results in a negative time shift.

The respective $\Phi_{m}$ and $M O b_{i m b}\left(S_{m i}\right)$ related contributions to the net time shift can also be observed by comparing cases 2 and 3 in Figure 20. Based on our observations, we would expect that increasing $\phi_{m}$ by a factor of two should have the effect of positively shifting time by $0.3 \log$ cycles. At the same time, our obscrvations also indicatc that increasing $S_{w 1}$ from 65 to 82.5 percent should have the effect of negatively shifting time by $0.17 \mathrm{log}$ cycles. In comparing cases 2 and 3 , we observe a nct positive time shift of 0.13 log cycles which is exactly what we get by adding the $\phi_{m}$ and $M o b_{m b}\left(S_{m}\right)$ related time shifts $(0.3-0.17=0.13)$. Therefore, for the plot of $\log d_{\text {imb }}$ versus $\log t$, we find that the mobility and porosity (or storativity) related contributions to the net timeshift are additive.

\subsection{The Decay of the Infiltration Slug in the Eracture}

ithus far we have only considered the saturation conditions which prevail during the "active" stage of the infiltration cvent. We now will consider what happens during the "passive" stage of Uic event: the period of ume following the removal of the infiltration saurce. Figures 21 and 22 are plots of the liquid saturation profile along the centerline of a 50 and 100 $\mu m$ fracture, respectively for the first 24 hours of the "passive" stage. As in Figures 13 and 14, longitudinal (i.c. vertical) distances are measured from the top of the fracture. We can sce in Figure 21 that after only 2 hours. imbibition by the adjoining matrix has reduced the saturation in the $50 \mu \mathrm{m}$ fracture to only 26 percent. After 24 hours, matrix imbibition has reduced the fracture saturation to less that 3 percent. After the removal of the infiltration source, matrix imbibition effectively arrests further downward movement of the infiltration slug in the 
fracture. The effect of gravity on the slug is marifested by "slumping" of the fracture saturation profile. panicularly for early time during the "passive" stage.

Relative to matrix imbibition, the effect of gravity in the $100 \mu \mathrm{m}$ fracture (Figure 22 ) is more pronounced than it is in the $50 \mu \mathrm{m}$ fracturc. The critical parameter here is the fracture aperture as it affects stomitivity (as opposed to hydraulic conductivity). It is important to note that the matrix imbibition flux per unit length of fracture is the same for these two cases. The ratio of the imbibition flux divided by the fracture storativity for the $10 X) \mu \mathrm{m}$ fracture is half that of the $50 \mathrm{\mu m}$ fracture. Consequently. after 2 hours the fracture saturation has only hecn reduced to 45 percent (as compared to 26 percent in the $50 \mathrm{\mu n}$ fracture) and the effects of "slumping" on the fracturc saturation profile are more apparent, panicularly for early time during the "passive" stage. The toe of the slug in the $100 \mathrm{~mm}$ fracture moves down the fracture an additional $5 m$ during the first 4 hours of the "passive" stage. After 24 hours, imbibition by the adjoining matrix has reduced the fracture saturation to less than 6 percent in the $100 \mu \mathrm{m}$ fracture (as compared to 3 percent in the $50 \mu m$ fracture).

From the foregoing discussion we can generalize that, because matrix imbibition dominates fracture flow during the "passive" stage of the event, gravity appears to play a minor role. A key quantity to be considered is the fraction of the cumulative infiltratien flux which remains in the fracture at the end of the "active" stage: obviously this fraction increases with fracture aperture. In Figure 23 we compare the matrix saturation profile, transverse to the fracture, obtained from two different models in order to isolate the contribution of the fracture storativity on matrix imbibition during the "passive" stage. Recall from Figure 17 that the "coarse mesh" one-dimensional matrix imbibition model and the "coarse mesh" twodimensional fracture/matrix model yield indiscemible matrix saturation profiles at the end of the "active" stage. For these same two models, the matrix saturation profile is plotted, 24 hours into the "passive" stage. The critical distinction between these two models is the manner in which the slug in the fracture is represented during "passive" stage. The two-dimensional model accounts for the presence of the slug at at the end of the "active" stage, thereby allowing it to be imbibed by the matrix during the "passive" stage. In the one-dimensional model, the slug is (effectively) instantaneously removed at the end of the "active" stage. thereby 
neglecting its contribution to imbibition during the "passive" stagc. The very small increment between the two curves $\left(50<\Delta S_{w}<100\right.$ percent) is the contribution of the fracture storativity on matrix imbibition during the "passive" stage. Regarding the assumptions built into the one-dimensional model, this increment represents the impact of neglecting the fracture storativity during the "passive" stage. It is apparent that for this particular case, the impact is negligible.

In Buscheck and Nitao (1988) it is shown that the abovementioned incremental contrit, 4 tion of the fracture storativity on matrix imbibition during the "passive" stage of the event is quantified by the normalized fracture infiltration front penetration depth $\bar{d}_{f}$. This quantity is defined to be the infiltration front penetration depth in a fractuse adjacent to an imbibing matrix divided by the infiltration front penetration depth in a fracture with impermeable walls. Hence, $\bar{d}_{f}$ is the ratio of the volume of water residing in the fracture divided by the cumulative infiltration flux which entered the top of the fracture. Conversely, $\left(1-\bar{d}_{f}\right)$ is the fraction of the total cumulative infiltration flux which resides in the matrix. Nitao and Buscheck (1988) found that for sufficienLy large times, $\bar{d}_{f}$ is proportional to $t^{-1 / 2}$. Applying thcir analysis to fractured welded tuff, it is found that $\bar{d}_{f}$ is relatively small even for $t=1$ hour. Thus, their analysis corroborates our observation that, relative to the cumulative infiltration flux, the contribution of the fracture storativity at the onset of the "passive" stage is negligible, thereby providing funher justification for the use of the one-dimensional approach.

\subsection{The Decay of the Imbibition Mound in the Matrix}

In Figure 24, the matrix saturation profile, transverse to the fracture, is plotted for several different times during the "passive" $s^{*}$ age of the infiltration event for the case where $\phi_{m}=20$ percent and $S_{m}=65$ percent. These curves were oblained from the one-dimensional malix imbibition model. Recall that in the previous subsection we were able to justify the use of the onc-dimensional approach to modeling the saturation distribution in the matrix during the "passive" stage. Morcover, in Figure 23 we observed that 24 hours into the "passive" stage, the matrix saturation profiles calculated by the one- and two-dimensinnal models are in close agreement. During the "active" stage the fracture/matrix contact is represented in the oncdimensional model by a computational boundary block which is maintained at $S_{w}=100$ 
percent and $P_{c}=0$ arm. By selting $S_{-}=0$ and $P_{c}=0$ in the bouncary block during the "passive" stage, the boundary ceases being a source of imbibition flux. At the same time the boundary block cannot be a capillary sink because $P_{c}=0$ and the pressurc in the neighboring matrix blocks are always $P \leq 1 \mathrm{arm}$. Consequently, during the "passive" stage this boundary acts as an impermeable barricr to liquid flow. The curves in Figure 24 are "snapshots" of the imbibition mound which is centered on the fracture as it decays into the surrounding matrix during the first year of the "passive" slage.

In both the one- and two-dimensional models the lateral boundary, which is opposite and parallel to the fracture, is a no-flow boundary located $0.25 \mathrm{~m}$ from the fracture midplane (or the constant potential boundary in the onc-dimensional model representing the fracture). The no-flow boundary in the matrix represents the plane of symmetry separating neighboring periodic fractures. Notice in Figure 24 that even almost one year into the "passive" stage, the periurbation to the saturation distribution has not yet reached the no-flow boundary.

\section{Interpreting Model Results With Respect to Geophysical Surveys}

\subsection{Geophysical Signature During the Decay of the Imbibition Mound}

We can use the foregoing information in considering the alterant tomographic signature of the "passive" stage of an episodic infiltration event. Recall that Ramirez and Daily (1985 and 1987) were working with $7.5 \mathrm{~cm} \times 7.5 \mathrm{~cm}$ tomographic pixcls. If we center such a pixel on the fracture, its "saturation measurement" would integrate saturation conditions out to $3.75 \mathrm{~cm}$ on either side of the fracture. We can sce in Figures 15 and 16 that the entire wetting zone straddling the fracture falls witnin this $7.5 \mathrm{~cm}$ wide pixel during the "active" stage. We can also see in Figure 24 that 8 days into the "passive" stage. the toe of the imbibition front will have reached the edge of this pixel. After the imbibition mound has decayed for 58 days, approximately 80 percent of it still lies within the pixel straddling the fracture with the remaining 20 percent lying within the neighboring pixel (i.e. the neighboring $7.5 \mathrm{~cm}$ wide band). Therefore, after approximately two months we would expect the lateral extent of the saturation perturbation to occupy the $22.5 \mathrm{~cm}$ wide band comprised of three $7.5 \mathrm{~cm}$ wide pixcls. After the imbibition mound has decayed for one year, the toc of the imbibition front is located 
approximately $0.2 \mathrm{~m}$ from the fracture midplane. Therefore the wetting zone lies entirely within a $52.5 \mathrm{~cm}$ wide band comprised of seven $7.5 \mathrm{~cm}$ wirle pixels.

We can also consider Figure 24 with respect to the averaging kernel for the neutron tool. In order for the following observations to be relevant to neutron surveys, we must first make scveral idealizations and assumptions. First, we assurne that the instrument borchole for the neutron survey is orthogonal to the fracture (or fractures) of interest. While some of the observations still qualitatively apply to a nonorthogonal borehole, orientations other than onhogonal significantly complicate quantitative interpretation. Secondly, we assume that we can preciscly locate the neutron tool such that the averaging kemel exactly straddles the fracture. We need to assume that the rock propenties within the kemel are homogeneous and that the ceniralizers position the neutron tool concentrically within the borehole. We also need to assume that the drilling fluid and grout used during the construction of the cased instrument borehole did not significanty perturb the saturation conditions within the averaging kemel. As mentioned carlier, nonhomogeneous saturation conditions within the averaging kemel may diston the shape of the kemel (from that of a sphere). Because most of our observations pertain to relativcly early time (i.e. when the welting zone about the fracture is still quite small relative to the radius of the averaging kemel), the disturbance to the initially homogeneous saturation distribution is probably insufficiert to significantly affect the shape of the averaging kemel. We therefore assume that the shape of the averaging kemel is spherical. As mentioned carlier, for the conditions which are anticjpated for both the prototype "heater" experiments in G-Tunnel and the EBDT at Yucca Mountain, the kemel radius is estimated to be $15 \mathrm{~cm}$. From Figure 24 we can see that even after the imbibition mound has decayed for nearly one year, the entire disturbance to the saturation field lics within the avcraging kemcl of the neutron tool.

\subsection{Geotomographic Signature of the Wetting Zone}

In interpreting the "geotomographic" signature of the saturation "hanges occurring during the "active" stage as well as the transition to the "passive" stage of an episodic infiltration event, we need to consider the liquid witer residing within the fracture as well as the water in the matrix. As mentioned carlier, an alterant tomograph, consisting of an array of pixcls, is a measure of saturation changes which have occurrcd between taking the "before" and "after" 
tomographs. Ramirez and Daily ([985 and 1987) have related anomalies in the alterant tomographic images to the flow of wates in fractures. Spatially, the perturbation in the saturation field can only be resolved down to the scale of an individual pixel. Of particular imponance is the fact that fracture flow occurring during the first few days of the event, as well as imbibition in the adjoining marix, occurs within a band which is narrower than the $7.5 \mathrm{~cm}$ width of a pixel. Consequenty, the alterant tomograph cannot directly resolve the width of the wening zone about the fracture. However, the magnitude of the measured change in the HFEM signal within a pixel, which we have hypothetically centered on the fracture, is indicative of the extent to which the fracture and matrix moisture conditions within that pixel have been perturbed. It is imporant to note that the change in the HFEM signal rate is sensitive to changes in water content (rather than changes in saturation). In order to calculate the corresponding change in saturation, we need to have data on the effective porositics of the fracture and matrix.

The curves in Figures 25 and 26 are intended to illustrate the sensitivity of the tomographic signature to saturation changes occurring within a $7.5 \mathrm{~cm}$ wide pixel centered on a fracture subjected to an episodic infiltration event. The curves is Figures 25 and 26 are based on cases 1 and 4 in Figure 20. The curves track changes in the normalized bulk saturation (defined below in Equation 9) for a $7.5 \mathrm{~cm}$ wide band straddling a fracture during an episodic infiltration event. The nomalized bulk saturation $S_{e b}$ takes into account saturation conditions within the fracture as well as those within the matrix as follows:

$$
S_{e b} \equiv \frac{\phi_{m}\left(1-\phi_{e f}\right)\left(S_{m}-S_{m i}\right)_{m}+\phi_{e f}\left(S_{w}-S_{m i}\right)_{f}}{\phi_{m}\left(1-\phi_{e f}\right)\left(1-S_{w i}\right)_{m}+\phi_{e f}\left(1-S_{w i}\right)_{f}}
$$

where the subscript $f$ denotes the fracture, $\phi_{\ell f}$ is defined to be the effective fracture porosity, calculated over the averaging volume of interest, and all other variables are as previously defined. It is imponant to understand the distinction between $\phi_{e f}$ and $\phi_{f}$ which is given by:

$$
\phi_{f}=\frac{b}{B}
$$

where $\mathrm{b} \equiv$ the fracture aperture and $\mathrm{B} \equiv$ the fracture spacing. While $\phi_{j}$ is an intensive property, intrinsic to the fractured rock mass, $\phi_{a}$ is an extensive property, dependent on the averaging volume over which it is calculated. We should also point out the subtle distinction 
between the manner in which $\phi_{f}$ and $\phi_{m}$ are defined. namely that $\phi_{m}$, is defined to be the matrix pore volume divided by the volume of the matrix (rather than the total volume of the fractured rock mass). An imporant requirement which must be met in calculating $\phi_{\ell}$ is that the diameter of the averaging kemel (e.g. the pixel diameler) be less than the fracture spacing.

Notice in Figures 25 and 26 that fracture apertures of 100 and $1000 \mu m$ are considered. We include the $1000 \mu \mathrm{m}$ fracture in deference to the observation by Neretneiks (1985) that hydraulic and volumetric fracture apertures may differ by one to two orders of magnitude. Time is measured relative to the arrival of the infiltrution front in the fracture at the axial location of our hypothetical $7.5 \mathrm{~cm}$ wide pixcl. We neglect the somewhat disperse shape of the infiltration front in the fraclure and the time it takes the infiltuation front to traverse the $7.5 \mathrm{~cm}$ dimension of the pixcl which is parallel to the fracture axis. Notice in Figure 14 that the time it takes the inflitsation front to reach a given axial location along the fracture within the likely domain of interest $(z \leq 10 \mathrm{~m})$ or traverse the $7.5 \mathrm{~cm}$ "axial" dimension of the pixcl is quite short relative to the time scale plotted in Figures 25 and 26 . Therefore, the time axes in Figures 25 and 26 would not be appreciably shifted if time were measured relative to the stan of the infiltration event at the top of the fracture.

At $s \leq 0$ hours, the saturation distribution in the matrix is unifom (al its jnitial or native value) and the fracture saturation is at its assumed native valuc of zero. Al s $=0$ hours, the fracture is instantancously filled with water (and maintained at 100 percent saturation), whereupon imbibition by the adjoining $\mathrm{m}_{c}$. . Sommences. At $r=48$ hours, the water in the fracture is instantancously removed, whereupon the imbibition mound in the matrix begins its decay laterally outward (away from the fracture). As seen in Figure 24 for $\phi_{m}=20$ percent and $S_{w i}=$ 65 percent, the entire imbibition mound remains within the $7.5 \mathrm{~cm}$ wide pixel for approximately eight days following the removal of the infiltration source. For $\phi_{m}=10$ percent and $S_{w 1}$ $=82.5$ percent, the entire imbibition mound remains within the $7.5 \mathrm{~cm}$ wide pixel for approximately four days following the removal of the infiltration source. Therefore, for the first 12 hours following the removal of the infiltration source ( $48<t \leq 60$ hours in Figures 25 and 26), the entire imbibition mound is contained entirely within our pixel. 
The imporant distinction between Figures 25 and 26 is that the cases in Figure 25 have four times the initially unsaturated matrix porosity $\phi_{m}\left(1-\phi_{f f}\right)\left(1-S_{w i}\right)$ than the cases in Figure 26. Consequently, changes in the normatized bulk saturation $\Delta S_{r b}$ are more heavily influenced by the effective fracture porosily $\phi_{t f}$ for the cases in Figure 26 than they are in Figure 25. Accordingly, the geotomographic signature of the infiltration event is more significantly influenced by changes in fracture saturation $\left(S_{w}-S_{w i}\right)_{f}$ for the cases in Figure 26 than it is in Figure 25. The influence of the fracture storativity is felt as a stepwise increase in normalized bulk saturation $\Delta S_{e b}$ as the fracture is instantaneously saturated at $t=0$ hours. For the cases in Figure 26 we find that $\Delta S_{e s}(t=0)$ is considerable larger $(7.1$ and 43.6 percent) than it is for the cases in Figure 25 (1.9 and 16.2 percent).

In comparing Figures 25 and 26 it should be noted that the magnitude of $\Delta S_{e b}$ cannot (by itself) be used to compare the anticipated magnitude of the geotomographic response for the cases in the respective Figures. For $0<t \leq 48$ hours, we see that the matrix imbibition related increase in $\Delta S_{x b}$ in Figure 26 (52.9 and 32.1 percent) is lasger than it is in Figure 25 (32.3 and 27.6 percent). However, because the initially unsaturated matrix porosity $\phi_{m}\left(1-\phi_{o f}\right)\left(1-S_{w i}\right)$ for Figure 25 is four times that for Figure 26, the resulting magnitude of the geotomographic response will actually be greater for the cases in Figure 25 . At $t=48$ hours, upon the instantaneous removal of the water in the fracture, we see for all cases that $S_{c b}$ steps down to a value equal to the matrix imbibition contribution to the net change in $S_{e b}$.

Observations which can be made conceming the influence of the fracture aperture on the geotomographic signature arise from the same storativity relationship noted above for $\phi_{m}\left(l-\phi_{e f}\right)\left(1-S_{w i}\right)$. The relative impact of the effective fracture porosity $\phi_{e f}$ on the geophysical signature is simply determined by the relative fracture contribution to the initially unsaturated porosity within the averaging volume of interest

$$
\gamma \equiv \frac{\phi_{e f}}{\phi_{m}\left(1-\phi_{e f}\right)\left(1-S_{m i}\right)_{m}}
$$

where $\gamma \equiv$ the initially unsaturated fracture to matrix storativity ratio. For larger $\gamma$ (comesponding to larger apenture fractures) a larger fraction of the normalized bulk saturation $S_{e b}$ within a $7.5 \mathrm{~cm}$ pixel will be instantaneously saturated at $t=0$ hours. Consequenty, the initial 
gcotomographic response for the larger aperture fractures in Figures 25 and 26 is more heavily influenced by $\phi_{\alpha}$. Accordingly, for the $1000 \mu \mathrm{n}$ fracture cases we see a much larger $\Delta S_{a b}(t=0)$ (which is 16.2 and 43.6 percent) than for the $100 \mu \mathrm{m}$ fracture cascs. where $\Delta S_{e b}(t=0)$ is 1.9 and 7.1 percent.

As the infiltration event continues, the subsequent increase in the magnitude of the measured change in the geotomographic signal will reflect ongoing imbibition, transyerse to the

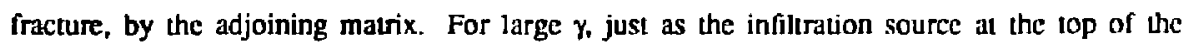
fracture is removed, there will be a more pronounced geotomographic response along the fracture, marked by a notable (stepwise) decrease in the wagnitude of the measured change in the HFEM signal. For small $\gamma$ (corresponding to smaller aperture fractures), changes in $S_{, b}$ will be dominated by the matrix porosity. Consequently, the gcotomographic response al $1=0$ hours will be less pronounced. As the infiltration event continues, the gcotomographic signature along the smaller apenture fracture will gradually increase, reflccling ongoing imbibition, transverse to the fracture, by the adjoining matrix. For small $\gamma$, after the infiltration source at the top of the fracture is removed, there will be a isss pronounced geotomographic response along the fracture, marked by a relatively minor (stepwise) decrease in the magnitude of the measured change in the HFEM signal.

\subsection{Neutron Tool Signature of the Wetting Zone}

Observations which can be made concerning the neutron tool signature of a fracture subjected to an episodic infiltration event are essentially the same as were already made for alterant geotomographic signature. Because the entire lateral extent of the wetting zone occurs within the width of one tomographic pixel during the "active" stage, the pixel can be considered to be an averaging kemel for any axial location along the fracture. The measured change in the geotomographic signal within a pixel is an integrated measurement of saturation changes averaged over that pixcl. Similarly, when "before" and "after" measurements are made with the neutron tool, the measured change in the ncutron count is indicative of saturation changes integrated over the averaging kemel. Figures 27 and 28 are plots of $S_{e b}$ versus time (within a $15 \mathrm{~cm}$ radius averaging sphere) for the same four cases considered in Figures 25 and 26. Notice that the shape of the curves are essentialiy the same as in Figures 25 and 26. 
The primary difference betwecn the geotomographic and neutron tool signature is in the magnitude of the change in $S_{a b}$. Because the neutron tool integrates the saturation changes over a much greater volume, the changes in the $S_{e b}$ are considerably less than they are for alterant geotomography. Consequently, the neutron tool may be less sensitive to saturation changes than is alterant geotomography. Therefore, a particularly important issue regarding the interpretation of neutron tool measurements of episodic infiltration events may be the signal to noise ratio.

\section{Summary and Conclusions}

A central issue to be addressed within the NNWSI Project is the role which fractures will play as the variably saturated, fractured rock mass surrounding the waste package responds to heating, cooling, and possible future recharge events. The development of validated performance assessment models will (in part) depend on our ability to experimentally observe, and appropriately model, the manner in which fractures affect perturbations in the moisture distribution. Among geophysical methods which appear to hold promise in monitoring the influence of fractures on moisture movement are the techniques of alterant geophysical tomography and neutron borehole logging. The geolomographic technique involves cross-borchole surveys, thereby providing an approximate two-dimensional perspective of moisture content changes over a relatively broad region of the fractured rock mass. By making HFEM measurements before and after the saturation field in the rock has been perturbed (the alterant technique), the manner in which the rock influences the signal is subtracted out; differences can be considered to be the geotomographic signature of changes in the moisture content. As an appropriate calibration algorithm becomes available, this geotomographic signature will then be translated to a two-dimensional map of saturation changes. The neutron tool provides an integrated measurement of moisture conditions within a spherical averaging kemel centered on the borehole. Neutron wool surveys are capable of logging variations in bulk moisture content as a function of axial position along the borchole.

Previous experimental studies of moisture movement in unsaturated. fractured, densely welded tuff involved alterant tomographs which consisted of arrays of $7.5 \mathrm{~cm} \times 7.5 \mathrm{~cm}$ pixels. Experience with neutron density surveys indicates that the radius of the averaging kemel will 
be approximately $15 \mathrm{~cm}$ in densely welded tuff. Given this scale of resolution, the primary objective of this study was to estimate the manner in which these geophysical surveys would "see" an episodic infiltration event along a fracture in densely welded tuff. To satisfy this objective it was necessary to study in detail the perturbation in the saturation ficld in the vicinity of the infiltration pulse in the fracture.

To model this system, we used LLNL's version of the TOUGH code. TOUGH is a multidimensional numerical simulator capable of modeling the coupled transport of water, vapor. air, heat, and aqueous phase constituents in fractured porous media. We considered a semiinfinite vertical fracture with periodic boundaries. Given these boundary conditions, we then only needed to model half of the fracture and half of the matrix lying between two identical fractures. The infiltration source located at the top of the fracture, is maintained at 100 percent saturation and a pressure of one atmosphere for the 48 hour "active" stage of the event. Due to the capillary discontinuity at the fracture/matrix interface, water may only reside (and thereby flow) in the fractures if the matrix immediately adjoining the fracture is ncarly fully sarurated. Consequently, under native saturation conditions, the fracture is drained of water.

The "active" stage of the infiltration event is marked by gravity driven flow down the fracture and matrix imbibition, transverse and adjacent to the fracture. During this lime it is found that much of the fracture flow is imbibed by the surrounding matrix, whercupon a symmetrical imbibition mound (centered on the fracture midplane) develops, spreading laterally outward. This spreading imbibition mound follows the infiltration pulse in the fracture, propagating at the same longitudinal velocity as the infiteration front in the fracture. We find at the same time that the longitudinal velocity of the infiltration front in the fracture is sensitive to the transverse imbibition rate in the matrix. Therefore, the longitudinal and transverse velocity of the imbibition mound in the matrix and the longitudinal velocity of the infiltration front in the fracture are interdependent.

For $t>48$ hours. the infiltration source at the top of the fracture is removed, commencing the "passive" stage of the event. Having had its source of water removed, the infiltration pulse only continues to propagate a relatively shon distance (if at all) down the fracture before 
being totally imbibed by the surrounding matrix. During the "passive" stage, gravity no longer plays a significant role and the symmetrical imbibition mound in the matrix decays laterally into the surrounding matrix.

Due to the absence of imbibition data for welded tuff, it was necessary to employ the concept of the hysteresis factor $\lambda$ developed in a previous study. In that study it was experimentally found that over a relatively broad range in matrix bulk saturation, the ratio of the imbibition and drainage suction pressures is a constant which we call the hysteresis factor $\lambda$. Moreover, we found that this broad range in matrix bulk saturation mone than adequately encompasses the range in matrix bulk saturation relevant to this study. We then applied $\lambda$ to the drainage moisture retention curve to obtain a moisture retention curve which is applicable to imbibition conditions. Because our calculations are quite sensitive to the imbibition flux in the matrix, the observations and conclusions drawn from our model results would have differed significantly had we not considered hysteresis.

Matrix imbibilion calculations were conducted using a one-dimensional imbibition model which approximated the interface with the infiltration pulse in the fracture with the use of a boundary maintained at 100 percent saturation and a pressure of one atmosphere. The matrix saturation profile nomal to the fracture face calculated with the one-dimensional imbibition model was compared with the profile obtained from the two-dimensional fracture/matrix model. It was found that for the region of interest $(z<10 \mathrm{~m}$ where $z$ is the longitudinal distance to the infiltration source at the top of the fracture), the matrix saturation profile transverse to the fracture is indiscernible from that predicted by the one-dimensional imbibition model. Consequently, we are able to use the one-dimensional matrix imbibition calculations in examining the parameter sensitivity of the width of the wetting zone as it follows the infiltration pulse in the fracture. We found that the width of the wetting zone is dependent on $\phi_{m}{ }^{-1 / 2}$. As with other diffusive phenomena, it was found that if we plot the log of marrix imbibition penetration depth versus the log of lime, the curves for all cases have a posilive slope of 0.5 . We also found that the initial matrix saturation $S_{m}$ affects the wetting zone width due to the dependence of the imbib:tion front mobility on $S_{m}$ (Equation 6). 
In considering the alterant tomographic signature of this episodic infiltration event, a critical observation is that for the first few days, the width of the wetting zone around the fracture is less than the width of a $7.5 \mathrm{~cm} \times 7.5 \mathrm{~cm}$ pixel. For the range in matrix properties considered, it takes from 4 to 8 days after removing the infiltration source for the width of the wetting zone to exceed the width of a pixel. Consequently, it is not possible for the alterant tomograph to directly resolve the width of the wetting zone until 4 to 8 days into the "passive" stage. However, the magnitude of the change in the HFEM signal within a pixel is indicative of the magnitude of saturation change within that pixel. Unless the fracture aperture is known, we cannot isolate the contribution of the fracture storativity on changes in the normalized bulk saturation $S_{e b}$. However, the manner in which $S_{e b}$ changes with time is characteristic of the relative contribution of $\phi_{e f}$ on changes in $S_{a b}$. If we (1) have reasonably good oata on the porosity and initial saturation in the matrix and (2) can correlate changes in HFEM signal to saturation changes, it may then be possible to approximately determine the volumetric fracture aperture from the plot of $S_{c b}$ versus time.

Following the removal of the infiltration source, the water in the fracture is quickly imbibed by the adjoining matrix, whereupon the imbibition mound around the fracture decays into the surrounding matrix. For approximately the first week of the "passive" stage of the infiltration event, the decay of the wetting zone will occur within the width of our hypothelical pixel, centered on the fracture. Thereafter, pixels on cither side of the "central" pixel will begin to "see" the wetting zone. After aboul one year of decay of the imbibition mound. for the case where $\phi_{m}=20$ percent and $S_{m i}=65$ percent, the lateral extent of the perturtation in the saturation field will occupy a band comprising seven $7.5 \mathrm{~cm}$ wide pixels. For the case where $\phi_{m}=10$ and $S_{w i}=82.5$ percent, it will take approximately 0.5 years for the lateral extent of the saturation perturbation to occupy the width of seven $7.5 \mathrm{~cm}$ wide pixcls. Consequenty, as the imbibition mound decays into the surrounding matrix, it may be possible to use the alterant tomograph to resolve the lateral extent of the saturation pertubation. These observations indicate that it may be useful to repeat geotomographic surveys several times during the year following the removal of the infiltration source. 
In closing, it should be cmphasized that the calculations and interpretations reported herein should be considered to be approximate estimates of how saturation changes will propagate along and adjacent to a fracture subjected to an episodic infiltration event. Because relevant matrix and fracture data is incomplete and therefore subject to uncertainty, we undertook a considerable effort to investigate and elucidate the functionality of the parameter sensitivity of fracture and matrix flow. Further treatment conceming the interaction of matrix and fracture flow is found Nitao and Buscheck (1988) and Buscheck and Nitao (1988).

\section{Acknowledgements}

The authors gratefully acknowledge helpful discussions with A. Ramirez and W. Daily at Lawrence Livermore National Laboratory. This work was support by the Exploratory Shaft task of the Nevada Nuclear Waste Storage Investigation Project al Lawrence Livermore National Laboratory.

\section{References}

Adamson, A. W., "Physical Chemistry of Surfaces", John Wiley and Sons, New York, N. Y., 664 p., 1982.

Aziz, K, and A. Seltari, "Petroleum Reservoir Simulation", Applied Science Publishers, Barking, Essex, England, 476 p., 1979.

Bear, J., "Hydraulics of Groundwater", McGraw-Hill, New York, 569 p., 1979.

Board, M. P., M. L. Wilson, and M. D. Voegel, "Laboratory Determination of Mechanicai, Ultrasonic, and Hydraulic Properties of Welded Tuff from Grouse Canyon Heated Block Site", SAND867130, Sandia National Laboratories, Albuquerque, N. M., 134 p., Augus! 1987.

Boltzmann, L., in Annalen der Physik and Chemie, Vol. 53, 959 p, 1894.

Buckley, S. E., and M. C. Leveret,, "Mechanism of Fluid Displacement in Sands". Transactions of AIME, Vol. 146, pp. 107-116, 1942.

Buscheck, T. A. and J. J. Nitao, "Fluid Flow Modeling", in Institutional Research and Development, FY86 Annual R.cport, UCRL-53689-86, Lawrence Livermore National Laboratory, Livermore, CA. pp. 48-49, 1987a.

Btischerik, T. A. and J. J. Nitao, "Estimates of the Hydrologic Impact of Drilling Water on Core Samples Taken from Partially Saturated Densely Welded Tuff", UCID-21294, Lawrence Livermore National Laboratory, Livennore, CA, $1987 \mathrm{~b}$.

Buscheck, T. A., and J. J. Nitao, "Estimates of the Impact of Drilling Water on the Near Field Hydrology for In Situ Experiments in Densely Welded Tuff", UClD- , Lawrence Livermore National Laboratory, Livermore, CA, 1988 (in preparalion). 
Daily, W., and A. L. Ramirez, "PJeliminary Evaluation of an Electromagnetic Experiment to Map In Situ Water in Heated Welded Tuff', UCRL.96816, Lawrence Livermore National Laboratory. Livermore, CA, 1987.

Daily, W., and A. L. Ramirez, "Water Imbibition by In Situ Grouse Canyon Densely Welded TurT", UCID. . Lawrence Livermore National Laboratory, Livermore, CA, 1988 (in preparation).

Dake, L. P., "Fundamentals of Reservoir Engineering", Developments in Petrolcum Science, 8, Elscvier Scientific Publishing Company, New York, N. Y., 443 p., 1978.

Edlefsen, N. E., and A. B. C. Anderson, "Thermodynamics of Soil Moislure", Hilgardia, Vol. 15, No. 2. pp. 31-298, 1943.

Edwards, A. L., "TRUMP: A Computer Program for Transient and Steady-State Temperature Distributions in Multi-Dimensional System", National Technical Information Service, UCRL-14754, Rev. II, Springfield, Virginia, 22151, 265 p., 1972.

Hillel, D., "Introduction to Soil Physics", Academic Press, Orlando, FLA, 364 p., 1982.

International Formulation Committec, "A Formulation of the Thermodynamic Properties of Ordinary Water Substance", IFC Secretariah, Dusseldor, Germany, 1967.

Klavetter, E. A., and R. R. Peters, "Estimation of Hydrologic Propertics of an Unsalurated, Fractured Rock Mass", SAND84-2642. Sandia National Laboratories, Albuquerque, N. M., 32 p., 1984.

Klinkenberg, L. J., "The Permeability of Porous Media to Liquids and Gasses", in: API Drilling and Production Practice, pp. 200-213, 1941.

Lawrence Livermore National Laboratory, "Test Plan: Prototype Engineered Barrier Design Testing • Horizontal Emplacement" in the Nevada Waste Management Program Quality Assurance Program Plan, Lawrence Livermore National Laboralory, Livermore, CA, Rev. 0, 033-NNwSI-p11.0, 1987.

Marshall, T. J., and J. W. Holmes, "Soil Physies", Cambridge University Press, Cambridge, England, 345 p.. 1979.

Mualem, Y., "A New Model for Predicting the Hydraulic Conduclivity of Unsaturated Porous Materials", Water Resources Research., Vol. 12, no. 3. pp. 513-522, 1976.

Narasimhan, T. N., and P. A. Witherspoon, "An Integrated Finite Difference Method of Analyzing Fluid Flow in Porous Media", Water Resources Research, Vol. 12, No. 1. pp. 57-66, 1976.

Neretneiks, I., "Transport in Fractured Rocks", Proceedings, Memoires of the 17th International Congress of IAH, Tucson, AZ, Vol. XVII, pp. 301-318, 1985.

Nitao, J. J., "Numerical Modeling of the Environment of a Nuclear Waste Package Using the Equivalent Continuum Approximation: Horizontal Emplacement", UCID-21444, Lawrence Livermore National Labotatory, Livermore, CA, 1988 (in preparation).

Nitao, J. J., and T. A. Buscheck, "On the Movement of a Liquid Front in an Unsaturated Fractured Porous Medium, Part I", UCID- , Lawrence Livermore National Laboratory, Livennore, CA. 1988 (in preparation).

Peters, R. R., E. A. Klavetter, I. J. Hall, S. C. Blair, P. R. Hellers, and G. W. Gee, "Fracture and Matrix Hydrologic Characteristics of Tuffaccous Matcrials from Yucca Mountain, Nye County, Nevada". SAND84-1471, Sandia National Laboratories, Albuquerque, N. M., December 1984.

Preuss, K. "Tough Uscr's Guide", LBL-20700, Lawrence Berkeley Laboratory, Berkeley, CA, November 1985.

Preuss, K., Y. W. Tsang, and S. Y. Wang. "Numerical Studies of Fluid and Heat Flow Near High-Level Nuclear Waste Packages Emplaced in Partially Saturated Fracturcd Tuff", LBL-18552, Lawrence Berkeley Laboratory. University of California, Berkeley. CA, 1984. 
Ramircz, A. L., and W. D. Daily. "Preliminary Evaluation of Alterant Geophysical Tomography in Welded Tuff", UCRL-92229, Lawrence Livermore Nauonal Laboratory, Livermore, CA, 9 p., 1985.

Ramirez, A. L, and W. D. Daily, "Evaluation of Alterant Gcophysical Tomography in Welded Tufr", Journal of Geophysical Rescarch, Vol. 92, No. B8, pp. 7843-7853, July 10, 1987.

Russo, A. J., and D. C. Reda, "Drying of an Initially Saturated Fractured Volcanic Tuff", SAND870293C. Sandia National Laboratories, Abuquerque, N. M., March 1987.

Sinnock, S., Y. T. Lin, and J. P. Brannen, "Preliminary Bounds on the Expected Postclosure Performance of the Yucca Mountain Repository Site, Southern Nevada", SAND84-1492, Sandia National Laboratories, Albuquerque, N. M., 1984.

Tsing. Y. W., and K. Prcuss, "A Study of Thermally Induced Convection Neur a High-Level Nuclear Waste Repository in Parially Saturated Fracured Tuff', SAND86-7010J, Sandia National Laboratories, Albuquerque, N. M., 1986 (also L.BL-21311).

Thordarson, W., "Gcohydrologic Data and Test Results from Well J-13, Nevado Test Site, Nye County, Nevada", Water Resources Investigations Report 83-4171, U. S. Geologi-zI Survey, Denver, CO, 1983.

Wang. S. Y., and T. N. Narasimhan, "Hydrologic Mechanisms Governing Fluid Flow in Partially Saturated. Fractured, Porous Tuff at Yucca Mountain", SAND84-7202, Sandia National LaboraLories, Albuqucrque, N. M., 45 p., April 1985.

Wang, S. Y., and T. N. Narasimhan. "Hydrologic Mechanisms Governing Partially Saturated Fluid Flow in Fractured Welded Units and Porous Non-Welded Units at Yurca Mountain”. SAND85-7114, Sandia National Laboratorics, Albuquerque, N. M., 69 p., Oclober 1986.

van Genuchten, M. Th., "A Closcd-Form Equation for Predicting the Hydraulic Conductivity of the Unsaturated Soils", Soil Sci. Soc. Am. J., Vol. 44, pp. 892-898, 1980.

Yow, J., Jr., "Concept for Waste Package Environment Tests in the Yucca Mountain Exploratory Shaft", UCID-20450, Lawirence Livermore National Laboratory, Ljvermorc, CA, 1985.

Zimmerman, R, M., and M. B. Blanford, "Expected Thermal and Hydrological Environments for Waste Emplacement Holes Based on G-Tunncl Heater Experiments". Proc. 27th Symposium on Rock Mcchanics, Chapter 125, pp. 874-882, 1986.

Zimmenman, R. M., F. B. Nimick, and M. B. Board, "Gcocnginecring Characterization of Welded Tuffs from Laboralory and Field Investigations". Proccedings of 1984 Symposium on Scientific Basis for Nuclear Waste Management VIIl, Materials Rescarch Society, Boston, MA, 1984.

Zimmerman. R. M., and R. E. Finley, "Summary of Gcomechasical Measurements Taken in and Around the G.Tunnel Underground Facility, NTS", SAND86-1015, Sandia National Laboratories, Albuquerque, N. M., 143 p., 1986. 


\section{Table 1}

Numericai Grid Spacing

for the Two-Dimensional Fracture/Matrix Model

(100 $\mu \mathrm{m}$ fracture)

Horizontal birection (mm)

\begin{tabular}{|c|c|c|c|c|c|}
\hline 0.05 & $2 \times 0.1$ & 0.2 & 6.4 & 0.8 & 1.6 \\
\hline $5 \times 3.2$ & 6.4 & 1.28 & 2.56 & 5.12 & 12.44 \\
\hline \multicolumn{6}{|c|}{ Verical Direction $(m)$} \\
\hline \multicolumn{6}{|c|}{$2 \times 0.5$} \\
\hline \multicolumn{6}{|c|}{1.0} \\
\hline & & & & & \\
\hline
\end{tabular}

Table 2

Numerical Grid Spacing

for the Two-Dimensional Fracture/Matrix Model

(50 $\mu m$ Iracture)

Horizontal Dircclion $(\mathrm{mm})$

\begin{tabular}{|l|l|l|l|l|l|}
\hline \hline 0.05 & $2 \times 0.1$ & 0.2 & 0.4 & 0.8 & 1.6 \\
\hline $5 \times 3.2$ & 6.4 & 1.28 & 2.56 & 5.12 & 12.44 \\
\hline \hline & Venical Direction (m) \\
\hline \hline
\end{tabular}

Table 3

Numerical Grid Spacing

for the One-Dimensional Matrix Imbibition Model

(fine mesh)

Horizontal Direction $(\mathrm{mm})$

\begin{tabular}{|l|l|l|l|l|l|}
\hline \hline 0.025 & $2 \times 0.1$ & 0.2 & $2 \times 0.4$ & 0.8 & $59 \times 1.0$ \\
\hline $20 \times 2.0$ & 4.0 & 8.0 & 16.0 & 32.0 & 64.00 \\
\hline
\end{tabular}




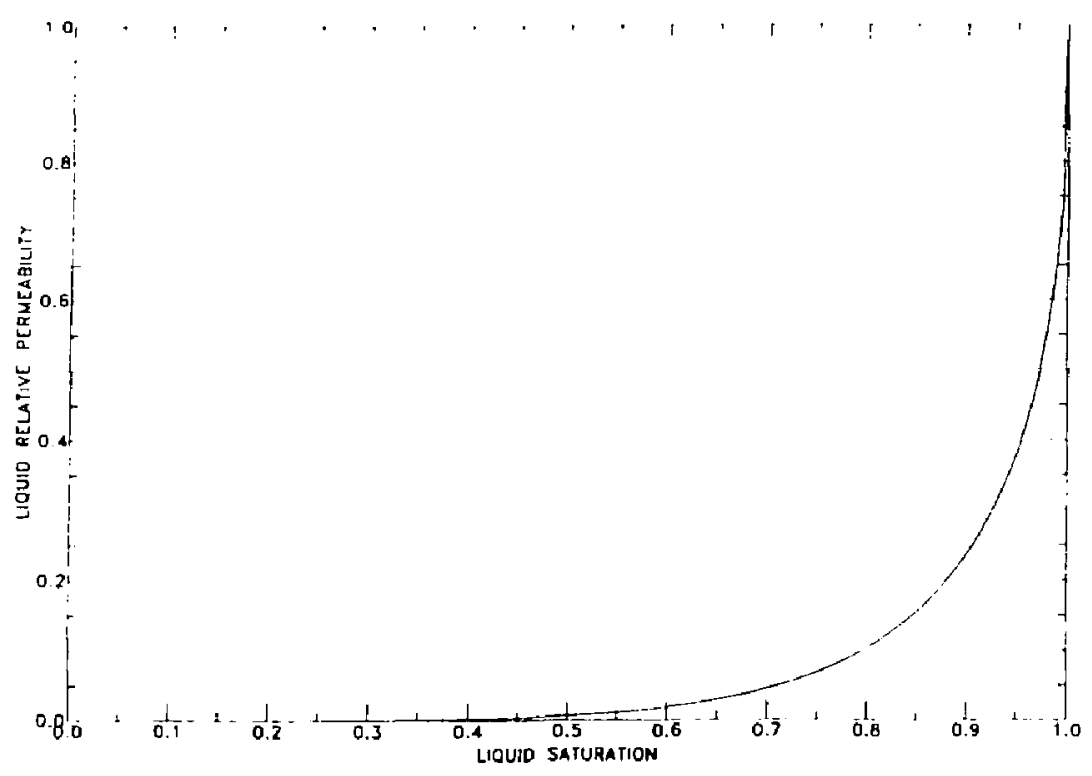

Figure 1. Liquid relative permeability versus liquid saturation for sample G4-6 cored at a depeh of 1158 fect within the repository horizon at Yucca Mountain.

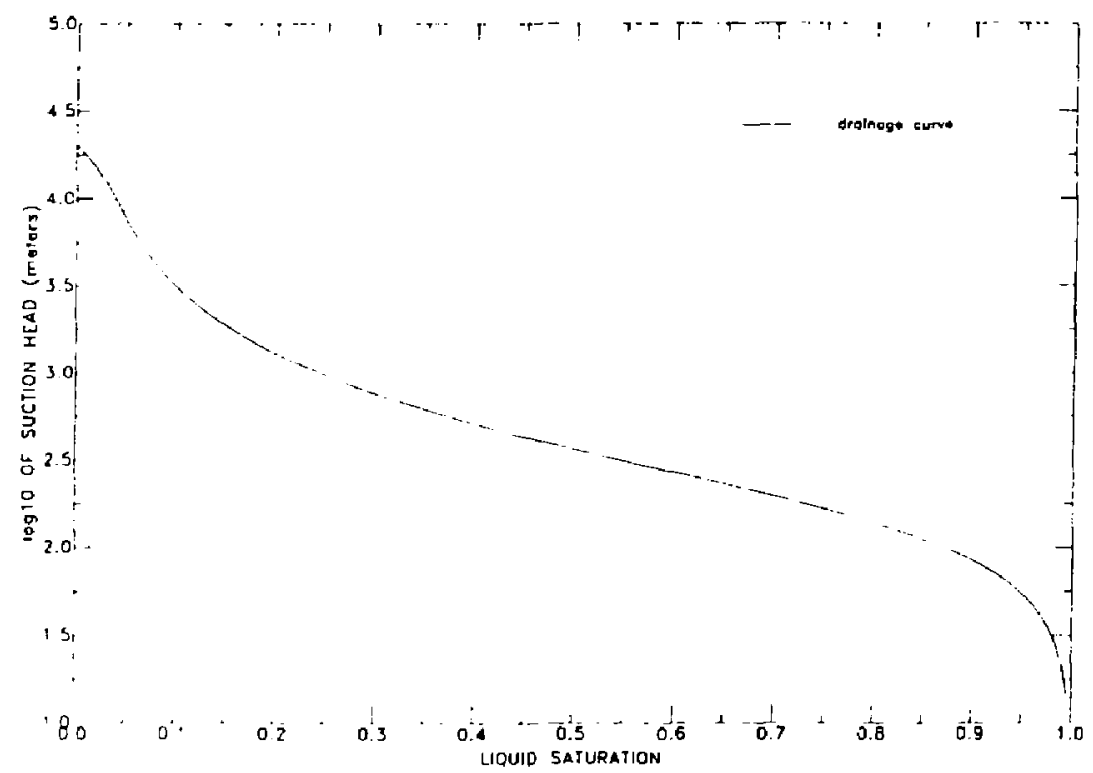

Figure 2. Log of the absolute value of suction head versus liquid saturation for sample G4-6 cored at a depth of $1158 \mathrm{fecl}$ within the repository horizon at Yucca Mountain. 


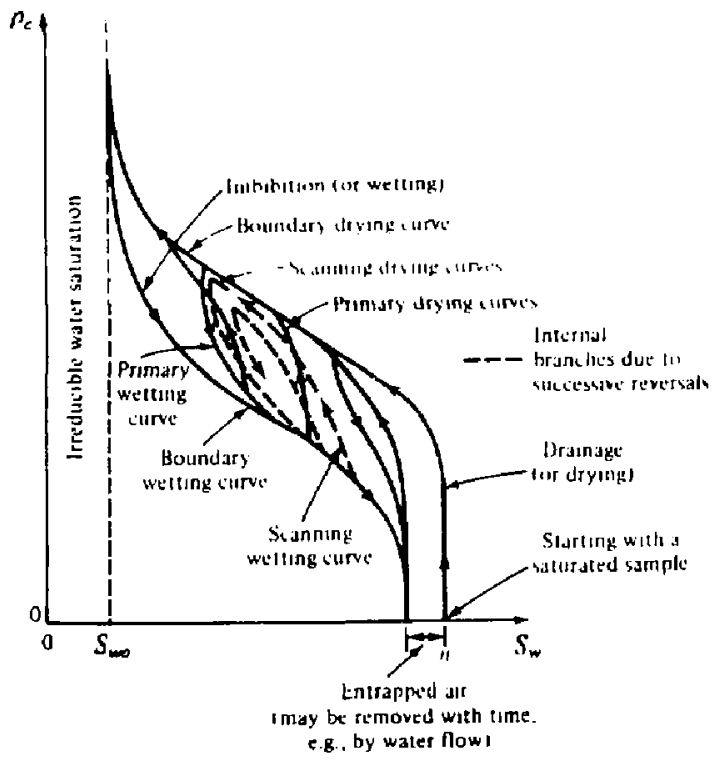

Figure 3. Hysteresis in the moisture retention curve (taken from Bear 1979).

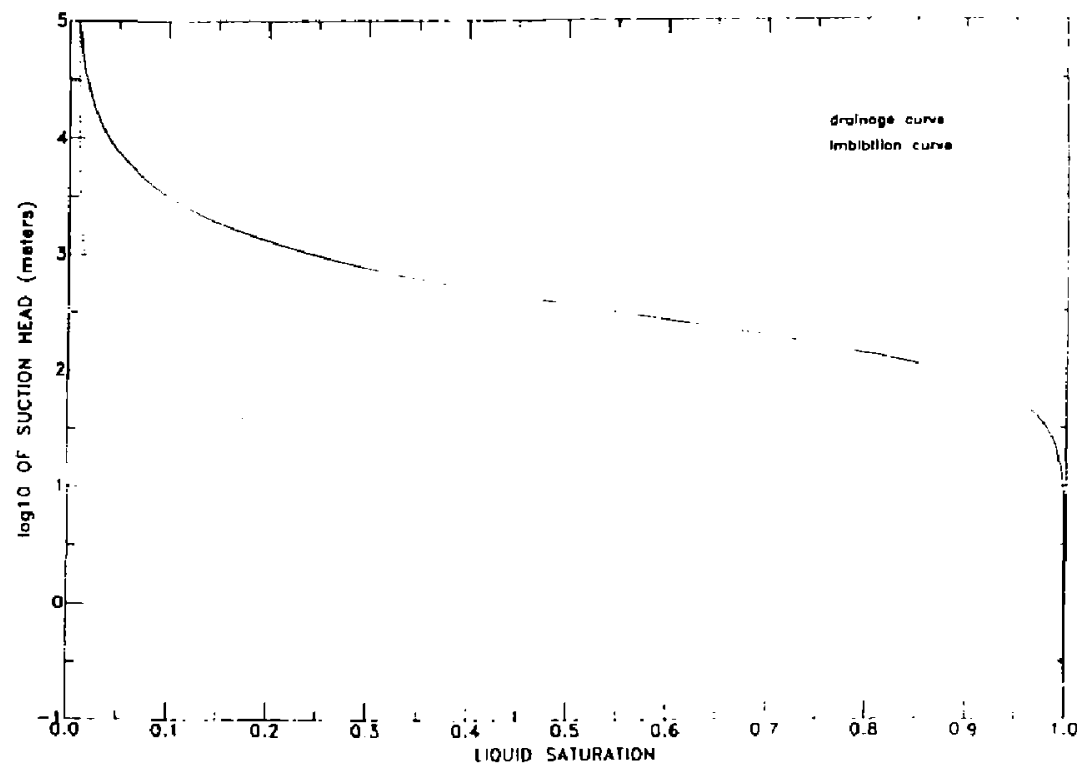

Figure 4. Hysteresis in the moisture retention curve. This example is an extrapolation of data observed in Buscheck and Nitao (1987). 


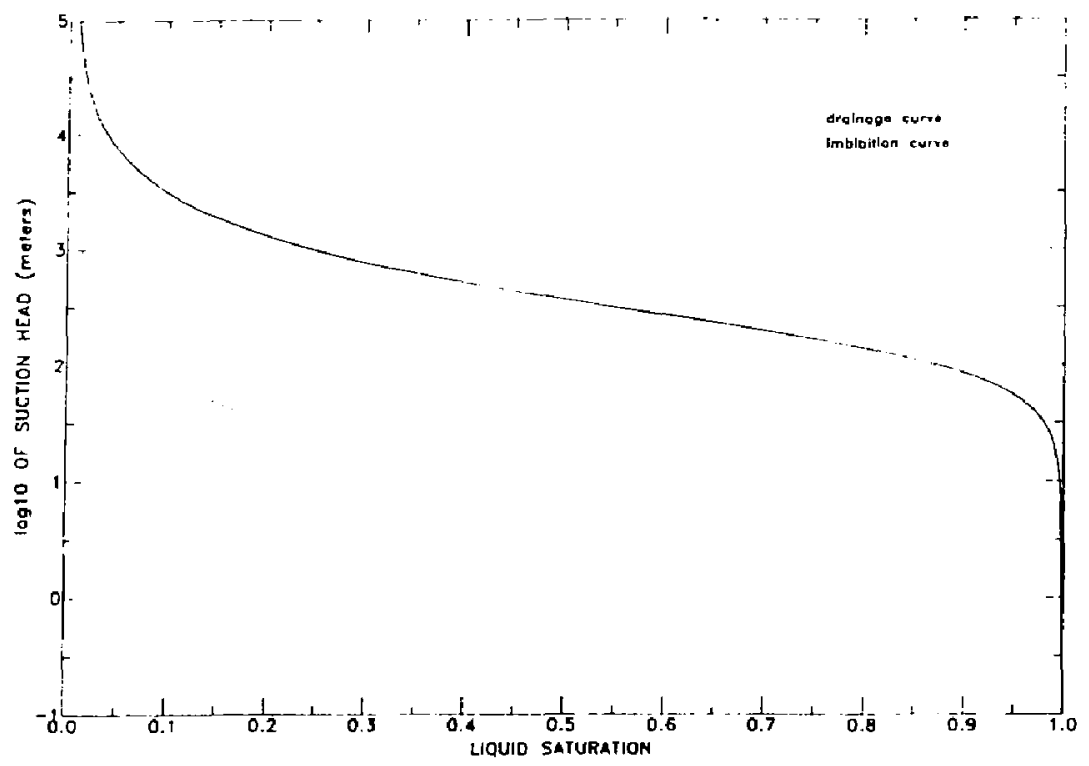

Figure 5. Hysteresis in the moisture retention curve. This example is an extrapolation of data observed in Buscheck and Nitao (1987) assuming that air entrapment occurs at 92\% saturation.

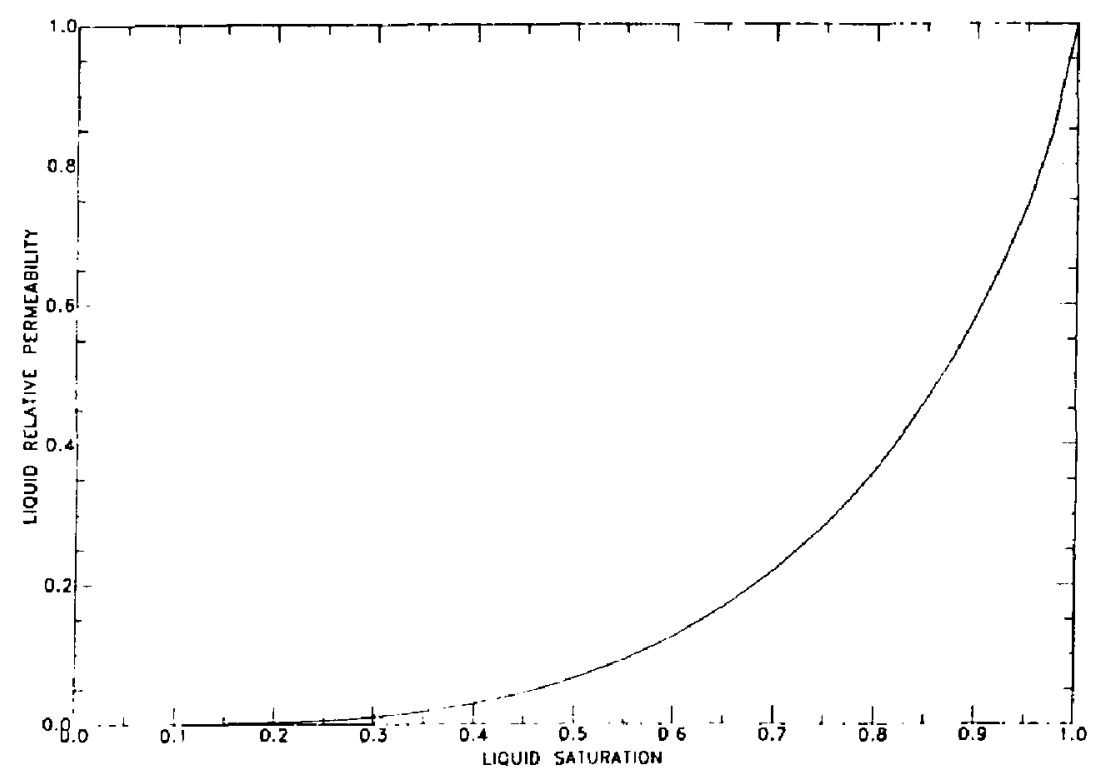

Figure 6. Liquid relative permeability versus liquid saturation for the 50 and $100 \mu \mathrm{m}$ fracture. 
-44 -

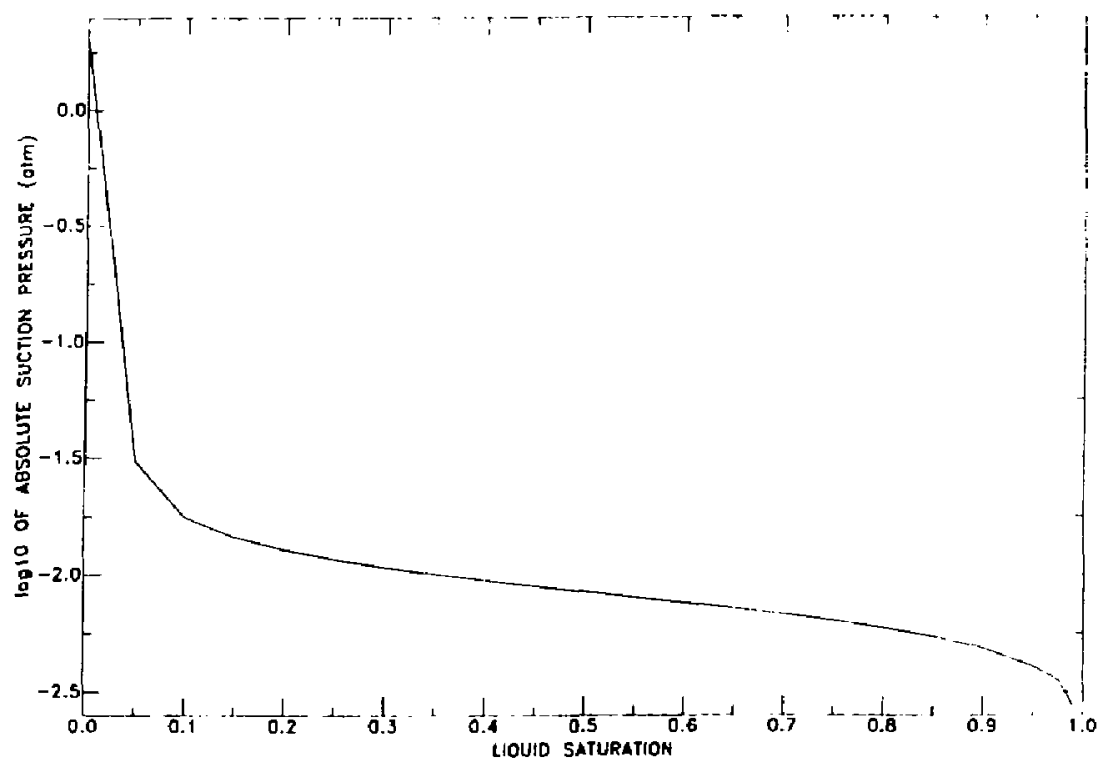

Figure 7. Log of the absolute value of suction pressure versus liquid saturation for the $100 \mu \mathrm{m}$ fracture.

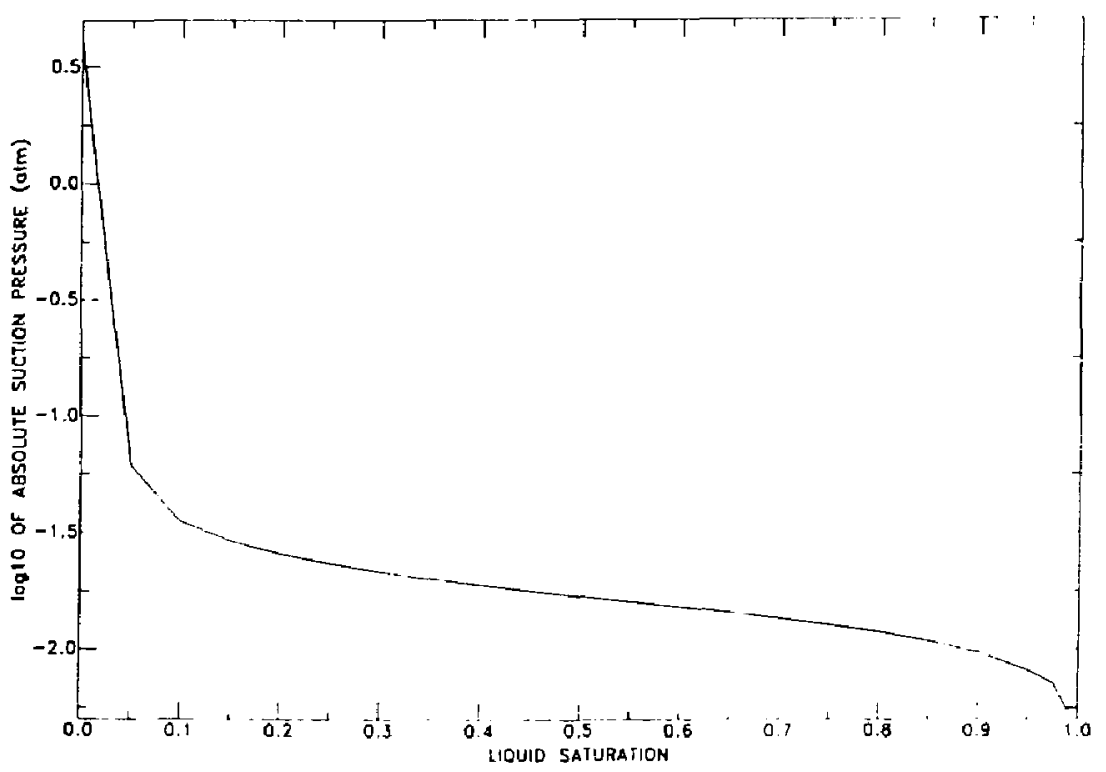

Figure 8. Log of the absolute valuc of suction pressure versus liquid saluration for the $50 \mathrm{\mu m}$ fracture. 


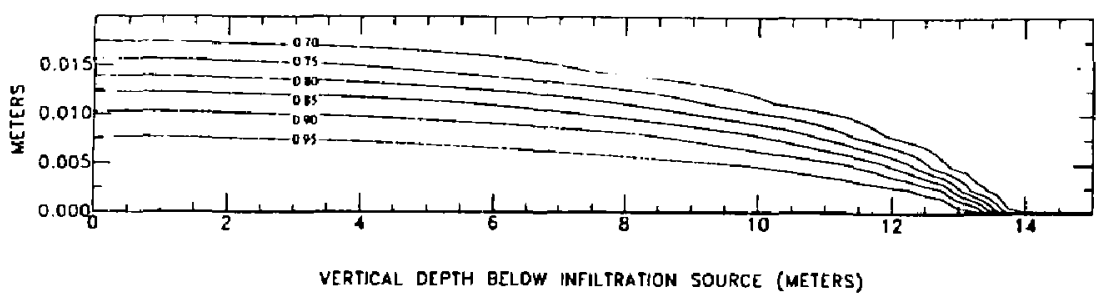

Figure 9. Liquid saturation distribution around a $50 \mu \mathrm{m}$ fracture at the end of the 2 day "active" stage of the infiltration event. Note that the figure is rotated $90^{\circ}$ counterclockwise and that horizontal distances are exaggerated by a factor of 143 .

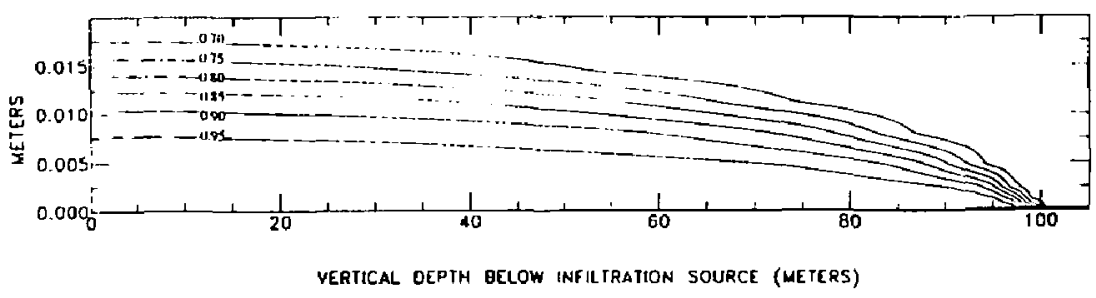

Figure 10. Liquid saturation distribution around a $100 \mu \mathrm{m}$ fracture at the end of the 2 day "active" slage of the infiltration event. Note that the figure is rotated $90^{\circ}$ counterclockwise and that horizontal distances are exaggerated by a factor of 1000 . 


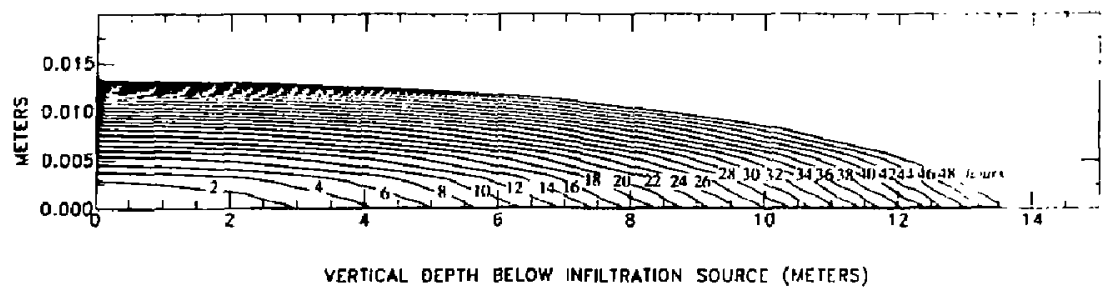

Figure 11. The $82.5 \%$ saturation contour in the vicinity of a $50 \mu \mathrm{m}$ rracture plotted cvery 2 hours during the 2 day "activc" stage of the infiltration event. Nore that the figure is rotated $90^{\circ}$ counterclockwise and that horizontal distances are exaggerated by a factor of 143 .

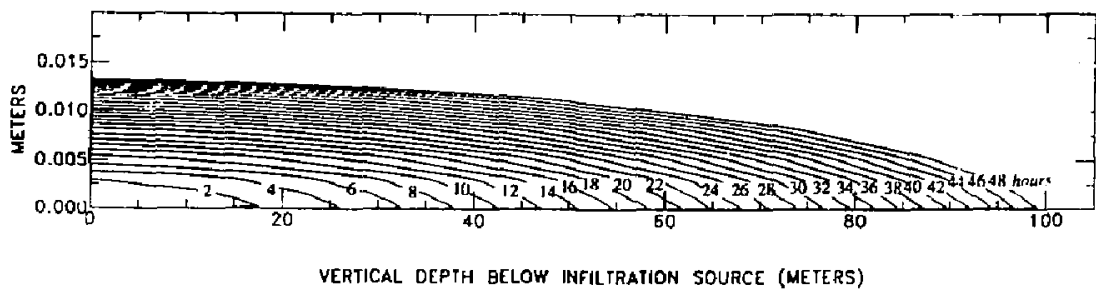

Figure 12. The $82.5 \%$ saturation contour in the vicinity of a $100 \mu \mathrm{m}$ fraclure plotted every 2 hours during the 2 day "active" stage of the infiltration event. Note that the figure is rotated $90^{\circ}$ counterclockwise and that horizontal distances are exaggerated by a factor of 1000 . 


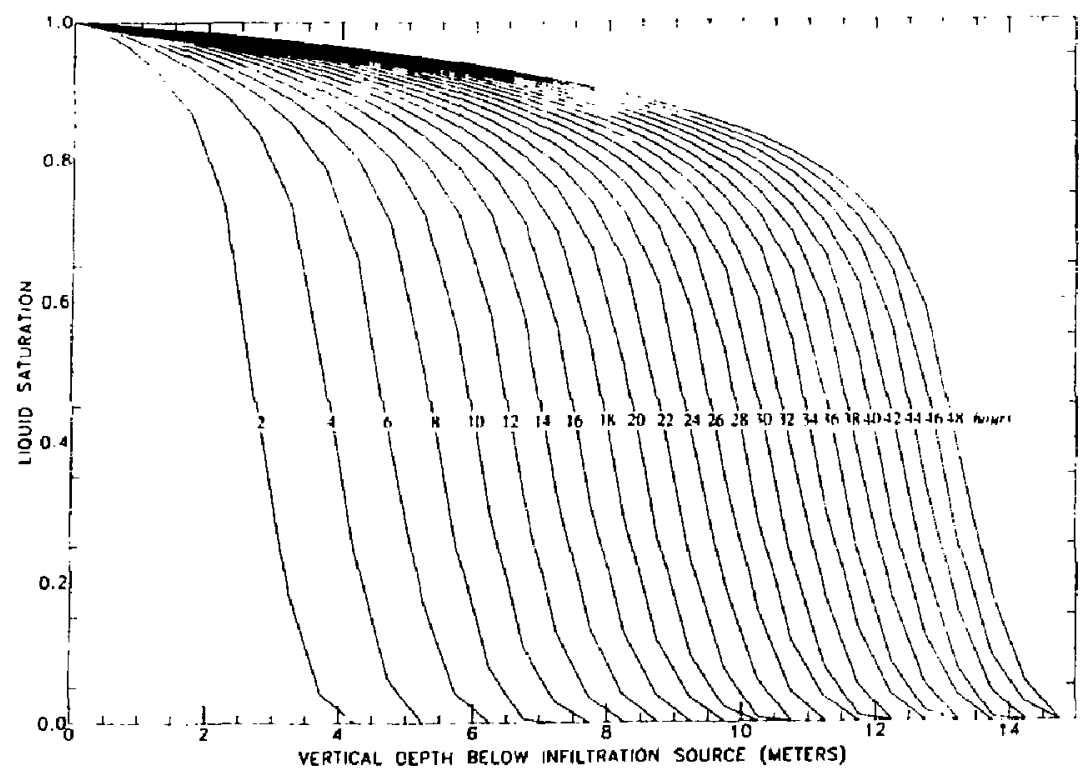

Figure 13. Liquid saturation profile along centerline of a $50 \mu \mathrm{m}$ fracture plotted as a furction of depth below the infiluration source. Curves are ploued every 2 hours during the 2 day "active" stage of the infiltration event.

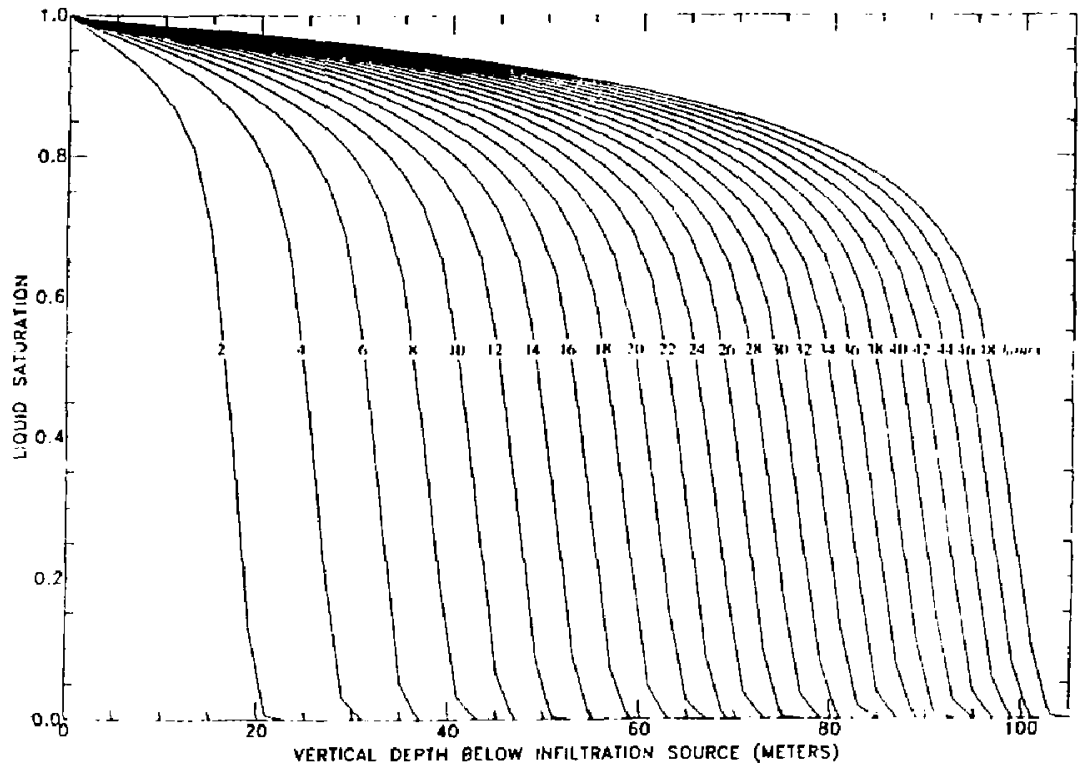

Figure 14. Liquid saturation profile along centerline of a $100 \mu \mathrm{m}$ fracture ploted as a funcion of depth below the infiluation source. Curves are ploted every 2 hours during the 2 day "active" slage of the initluation event. 


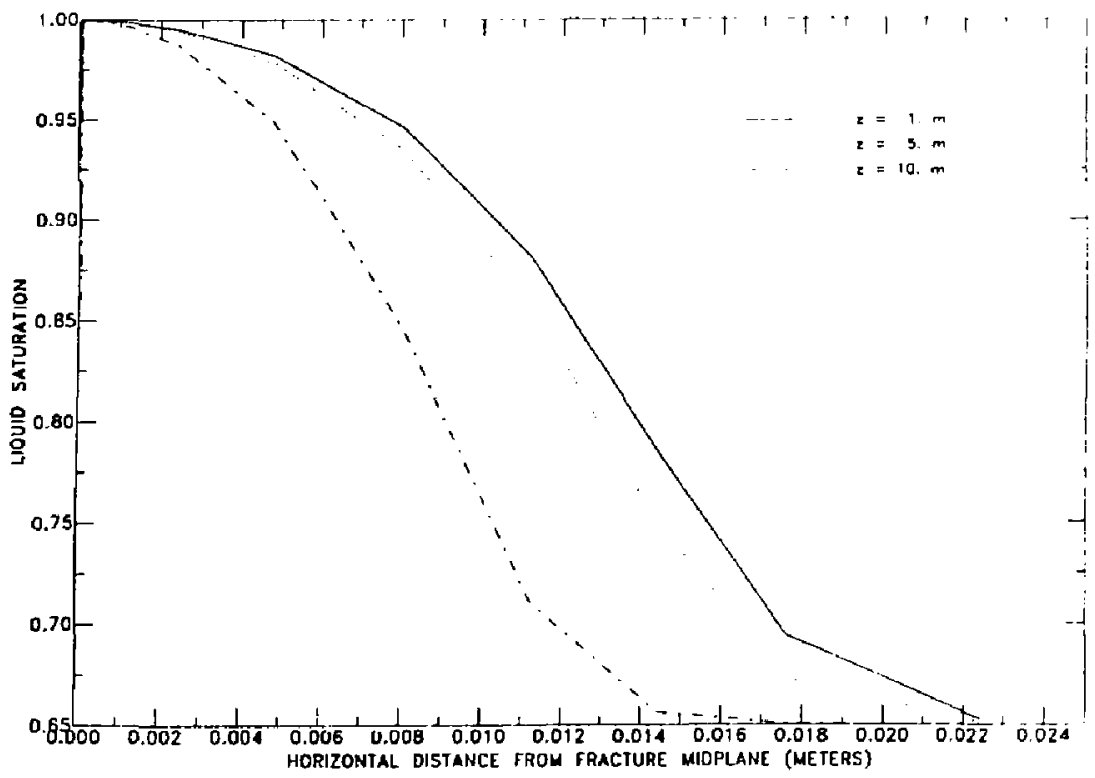

Figure 15. Liquid saturation profile in matrix plotted nomal to a $50 \mu \mathrm{m}$ fracture at the end of the 2 day "acive" stage of the infiltration event. Curves are plotted at depths of 1,5 , and $10 m$ bclow the infiltration source.

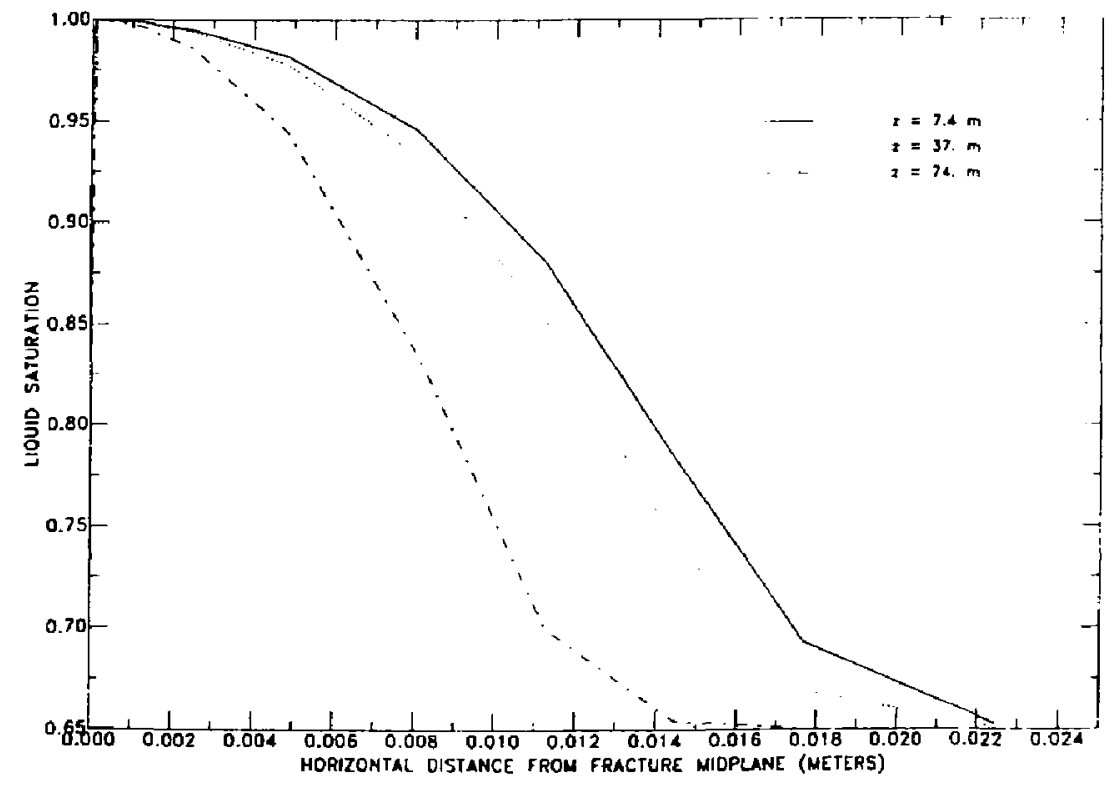

Figure 16. Liquid saturation profile in matrix plotled normal to a $100 \mu \mathrm{m}$ fracture at the end of the 2 day "active" stage of the infiltuation event. Curves are plotted at depths $97.4,37$, and $74 \mathrm{~m}$ below the infiluration source. 
$-49-$

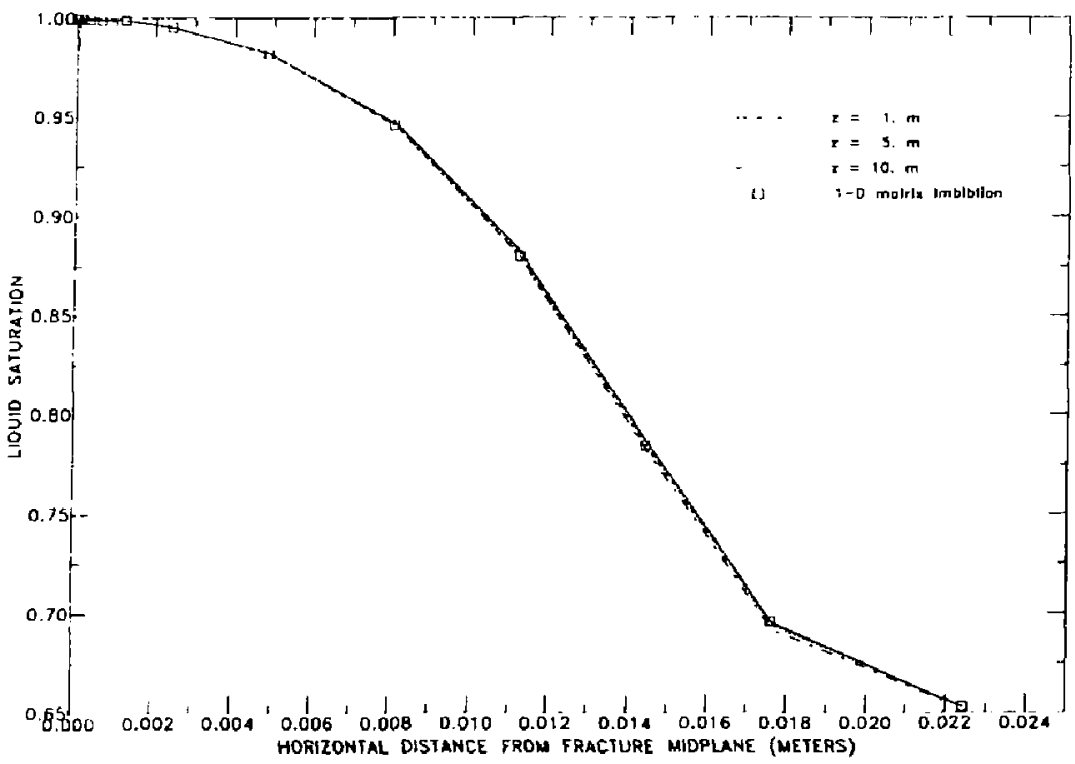

Figure 17. Liquid saturation profile in matrix plotled normal to a $100 \mathrm{\mu m}$ fracture at the end of the 2 day "active" stage of the infiltration event. Curves are plotted at depths of 1,5 , and $10 \mathrm{~m}$ below the infiltration source.

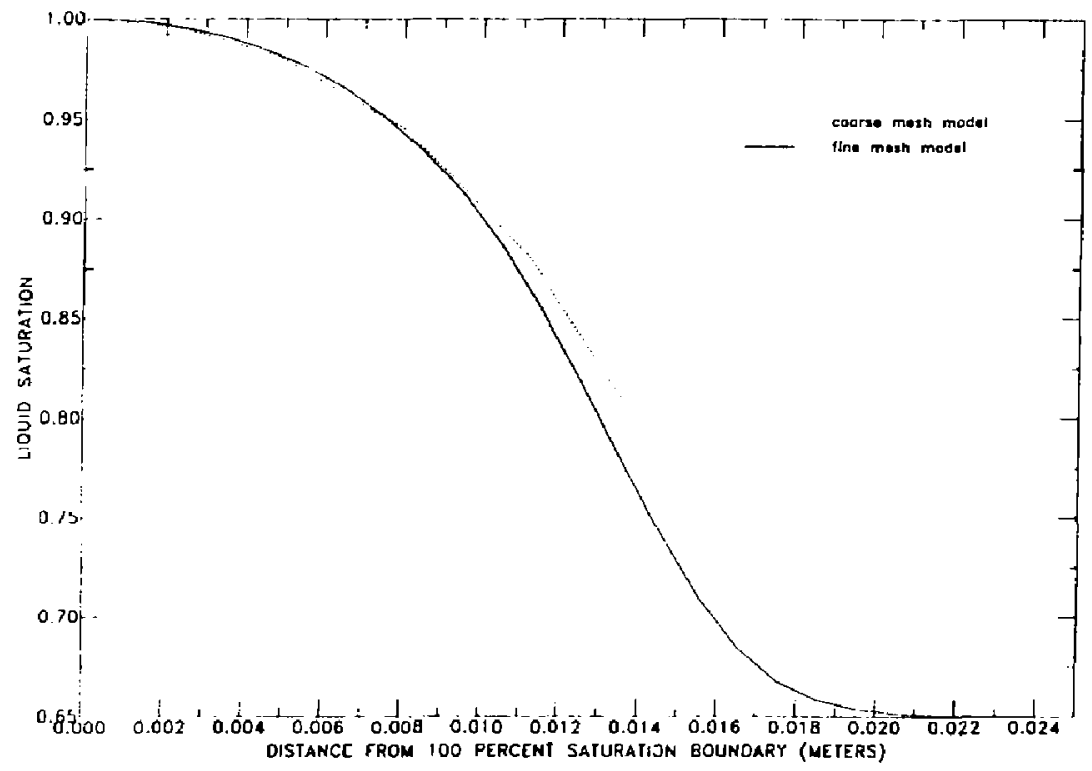

Figure 18. Liquid saturation profile for 1-D matrix imbibition normal to a fully saturalcd boundary Course mesh model uses horizontal grid spacing of the 2-D fracture/matrix model. 


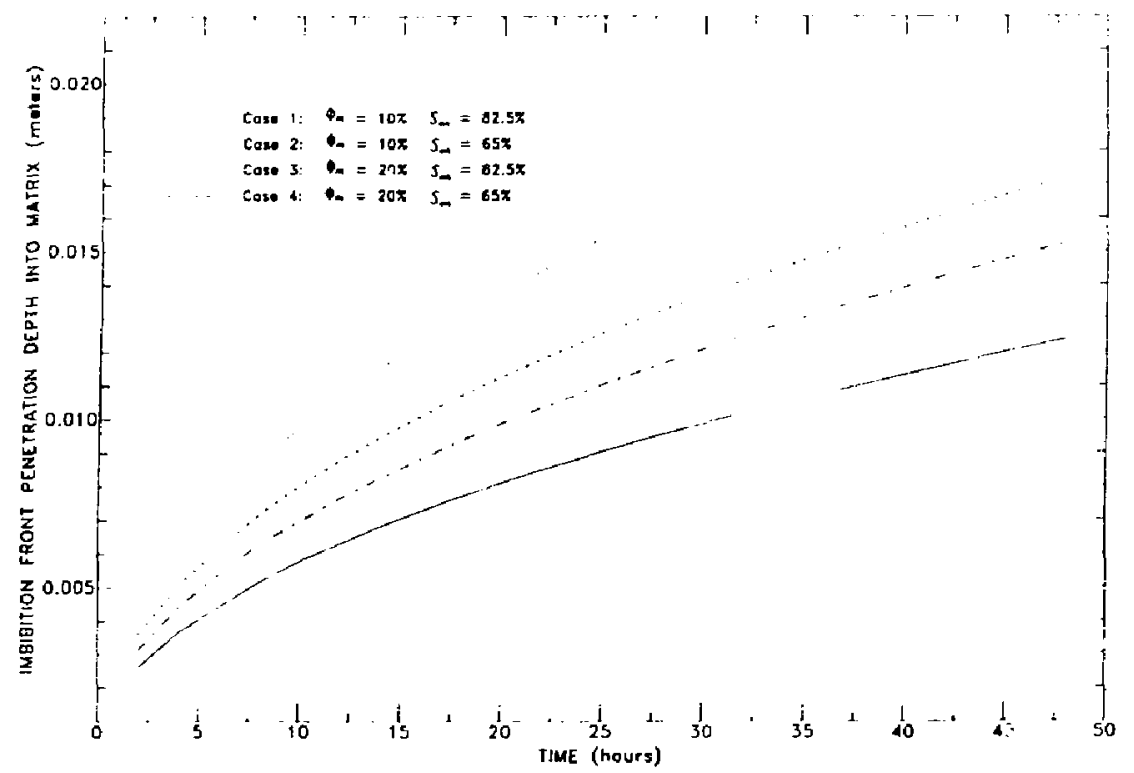

Figtre 19. Imbibition front penetration depth into matrix versus time. Note that distances are measured from the fully saturated boundary.

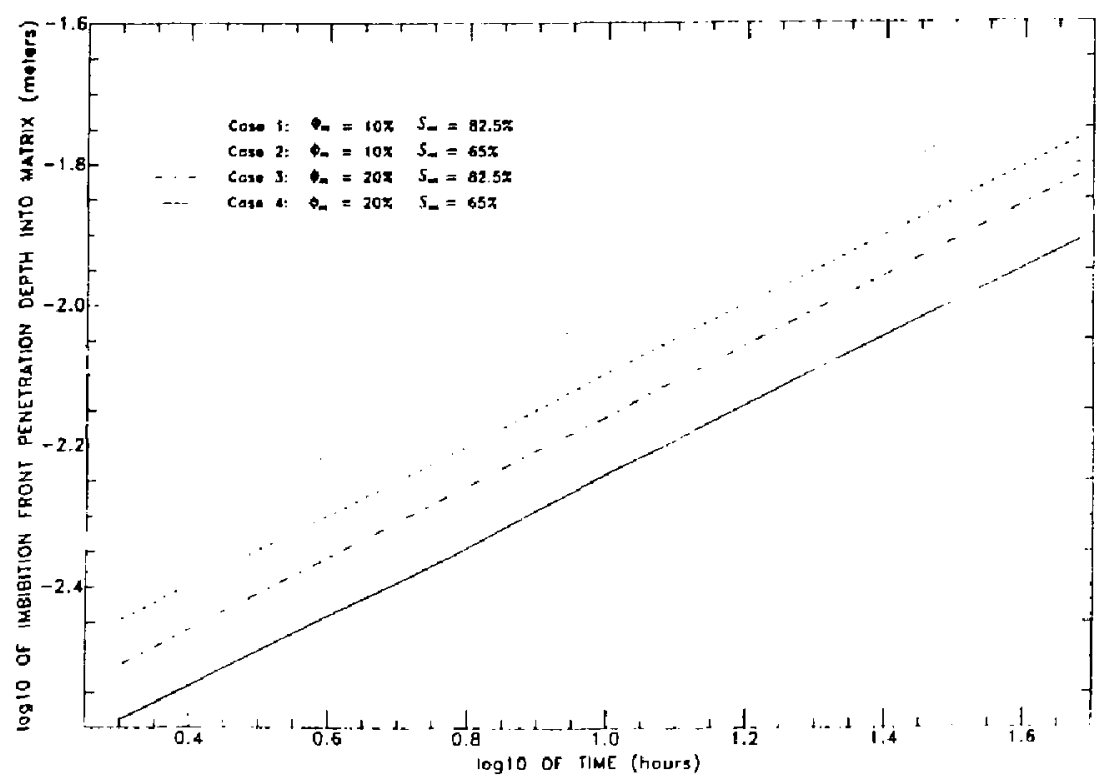

Figure 20. Log of imbibition front penctration depth into matrix versus log of time. Nore that distances are measured from the fully saturatod boundary. 


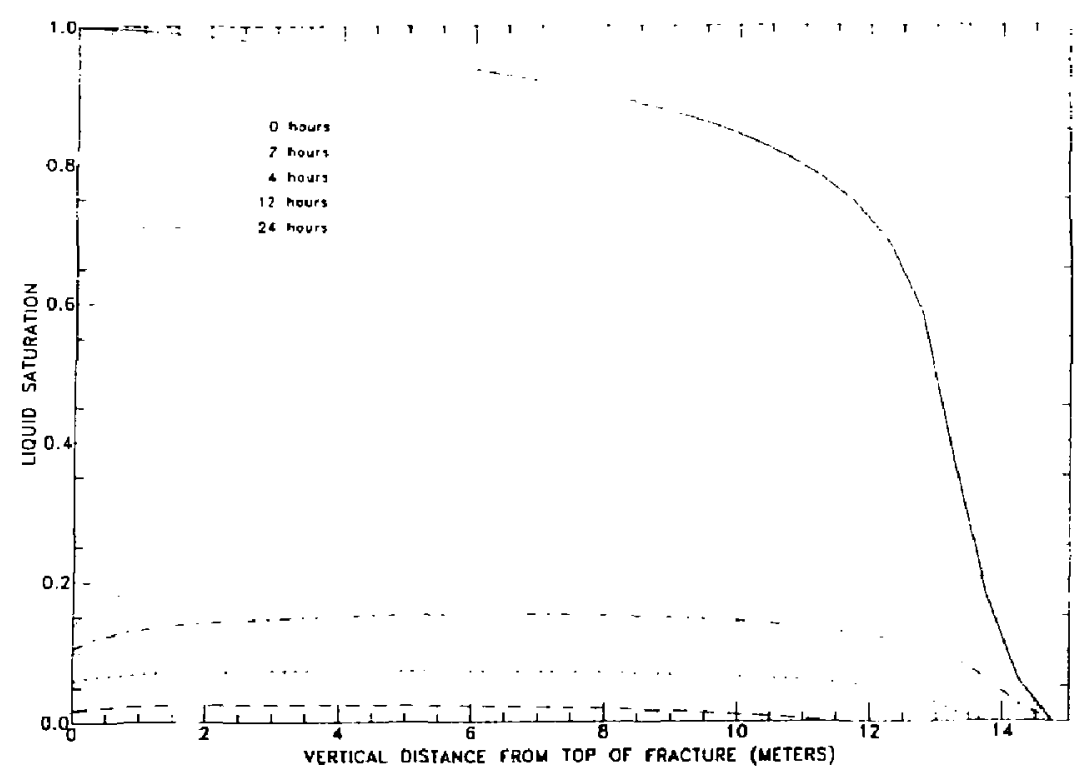

Figure 21. Liquid saturation profile along centerline of a $50 \mu \mathrm{m}$ fracture $0,2,4,12$, and 24 hours after the removal of the infiltration source for $\phi_{m}=20 \%$ and $S_{w i}=65 \%$.

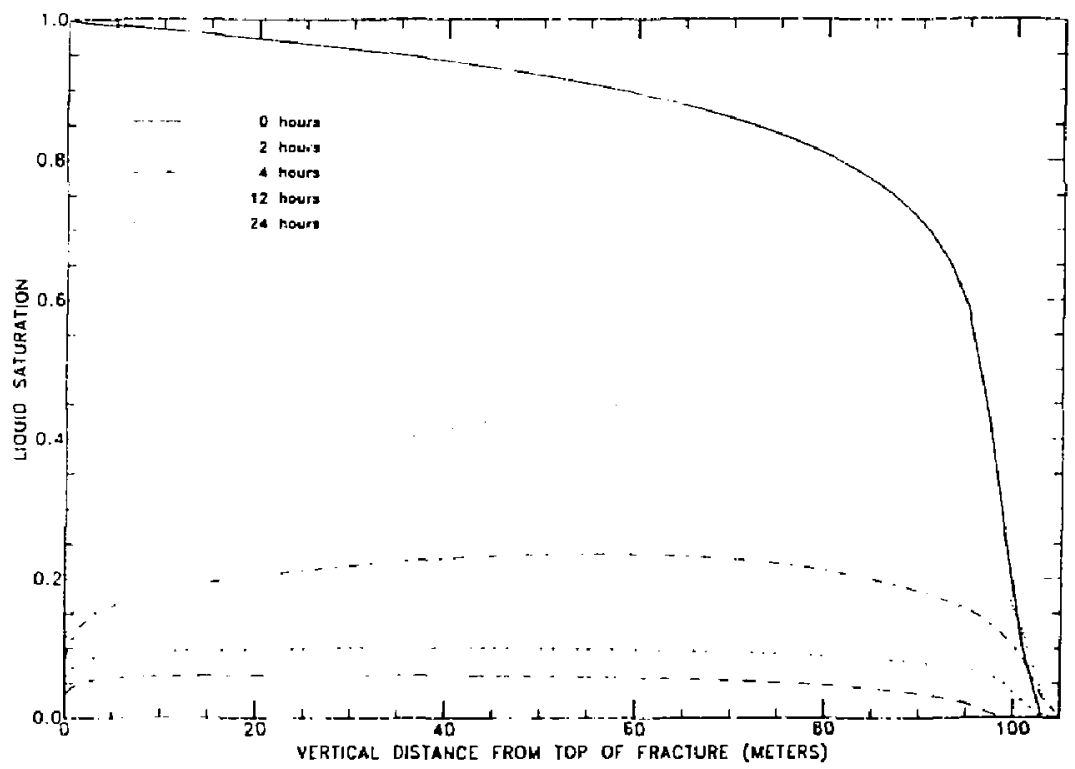

Figure 22. Liquid saturation profile along centerline of a $100 \mu \mathrm{m}$ fracturc $0,2,4,12$, and 24 hours afier the removal of the infiltration source for $\phi_{m}=20 \%$ and $S_{w i}=65 \%$. 
$0.75+$

0.70

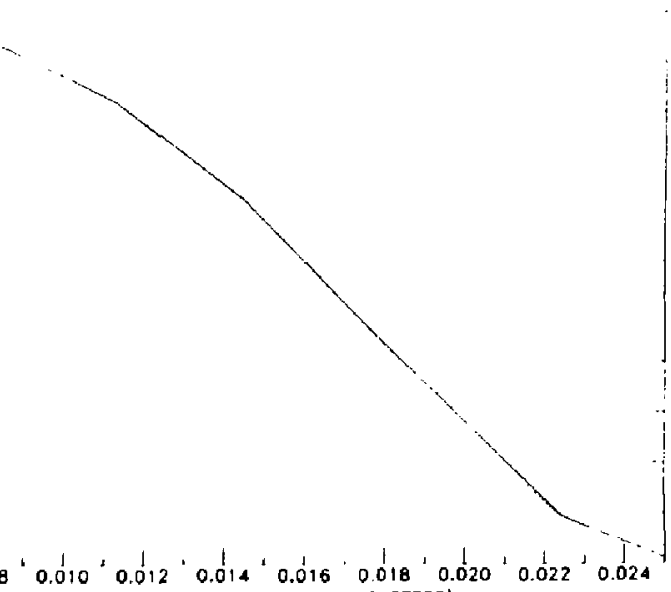

HORIZONTAL DISTANCE FROM FRACIURE MIDPLANE (METERS)

Figure 23. Liquid saturation profile in matrix plouted normal to fracture face 24 hours after the removal of the infiltration source for $\phi_{m}=20 \%$ and $S_{m i}=65 \%$ as predicted by the "coarse" mesh versions of the two-dimensional fracture/matrix model and the one-dimensional matrix imbibition model.

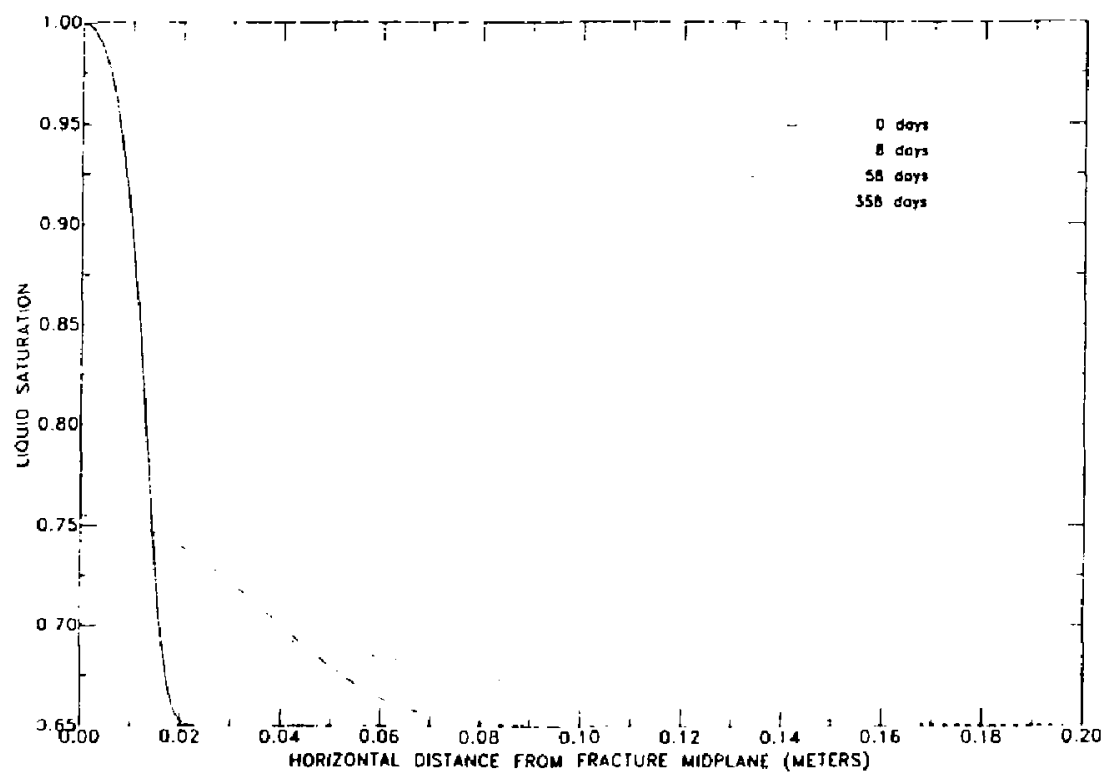

Figure 24. Liquid saluration profile in matrix platted normal to frateurc face $0,8,58$, and 358 days after the removal of the infiluation source for $\phi_{m}=20 \%$ and $S_{m-1}=65 \%$, 


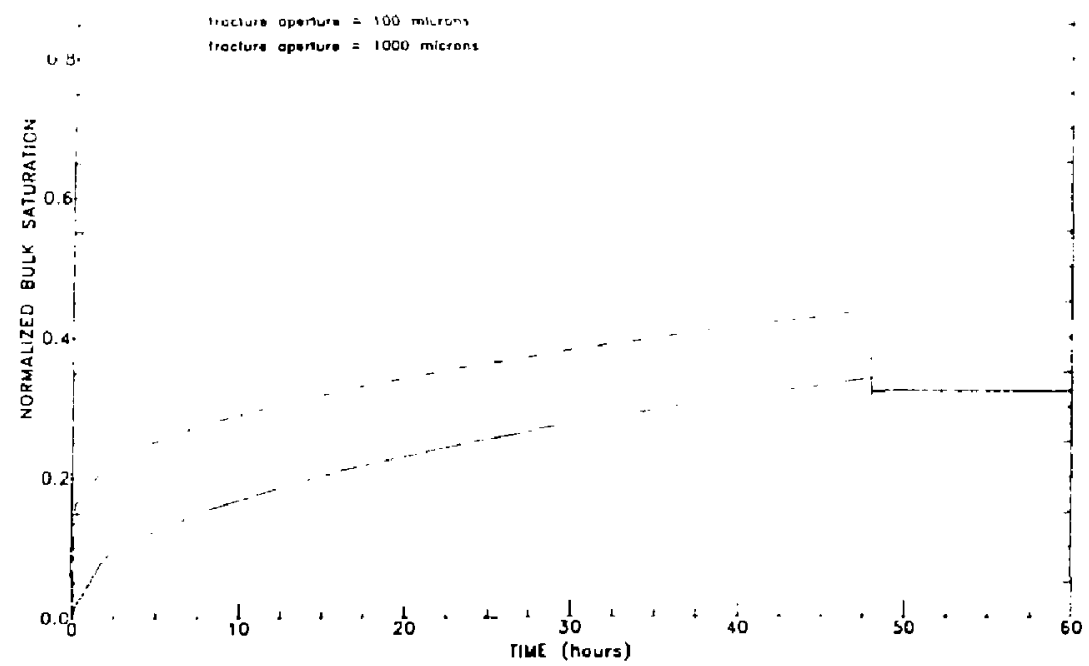

Figure 25. Normalized bulk saturation versus time within a $7.5 \mathrm{~cm}$ band straddling the fracture for aperuures of 100 and $1000 \mu \mathrm{m}, \phi_{m}=20 \%$, and $S_{m i}=65 \%$.

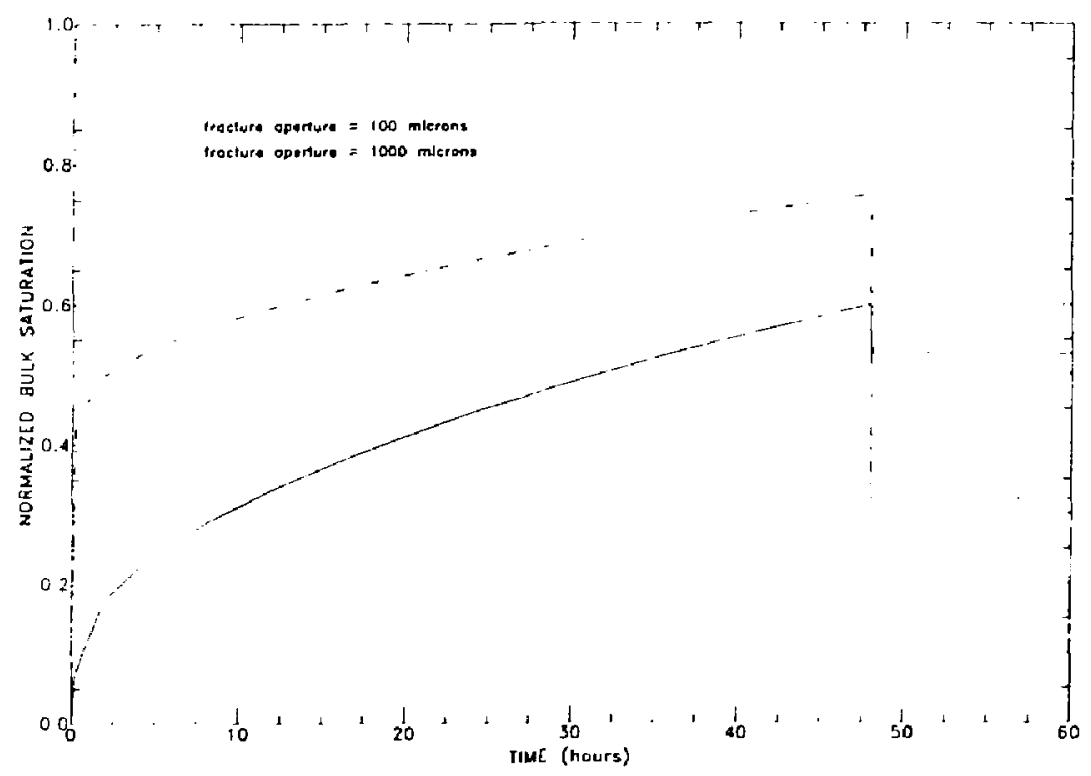

Figure 26. Normalized bulk saluration versus ume within a $7.5 \mathrm{~cm}$ band straddling the fracture for apertures of 100 and $1000 \mu \mathrm{m}, \phi_{m}=10 \%$, and $S_{m}=82.5 \%$. 


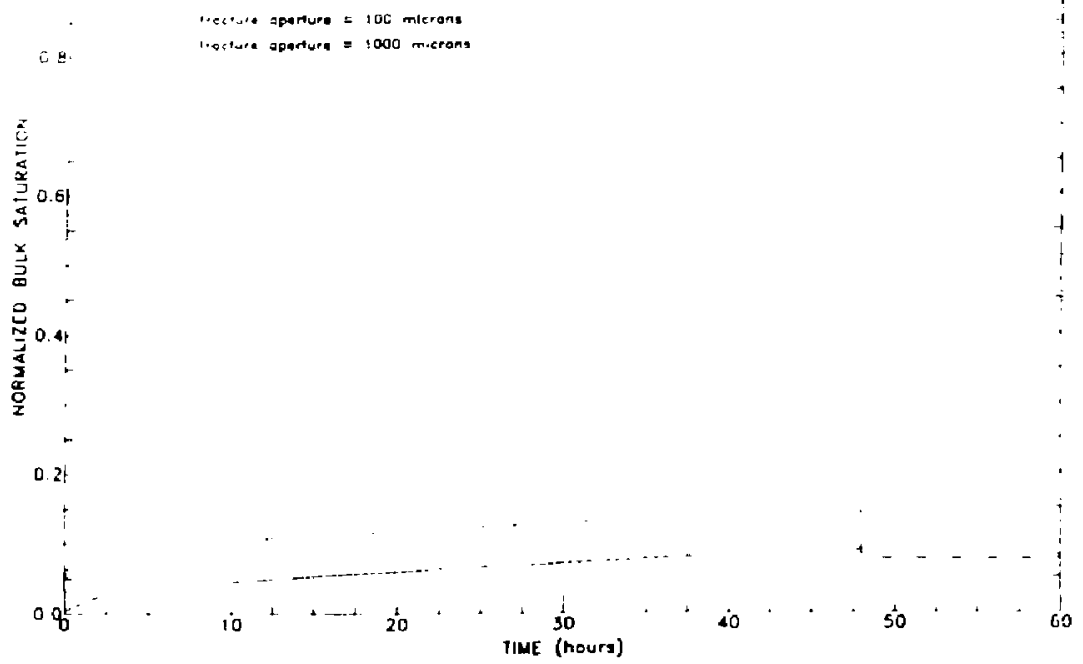

Figure 27. Normalized bulk salumion versus time within a $15 \mathrm{~cm}$ radius spherical averaging kemel straddling the fracture for apcrtures of 100 and $1000 \mu \mathrm{m}, \phi_{m}=20 \%$, and $S_{m}=65 \%$.

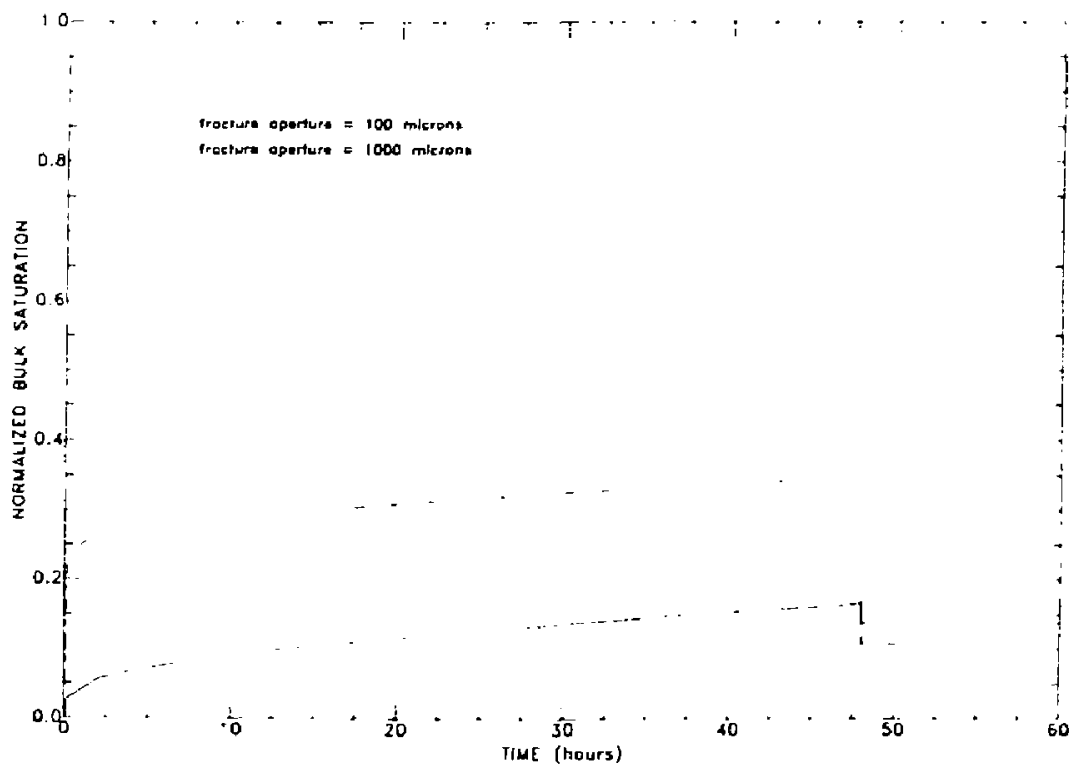

Figure 28. Normalized bulk saturation versus ume within a $15 \mathrm{~cm}$ radius spherical averaging kemel straddling the fracture for apertures of 100 and $10 \% 1 \mathrm{\mu m}, \phi_{m}=10 \%$, and $S_{-x}=82.5 \%$. 